\title{
Estilo de liderança, assimetria de informação e uso avaliativo do orçamento constituem-se antecedentes a participação orçamentária?
}

Leadership style, information asymmetry and evaluative use of the budget are antecedents of budget participation?

¿Estilo de liderazgo, asimetría de información y uso evaluación del presupuesto se constituyen antecedentes la participación presupuestaria?

\section{Micheli Aparecida Lunardi}

Mestra em Ciências Contábeis pelo Programa de Pós-Graduação em Ciências Contábeis da Universidade Regional de Blumenau (PPGCC/FURB)

Endereço: Rua Antônio da Veiga, $n^{\circ}$ 140, Bairro Victor Konder

CEP 89012-900 - Blumenau/SC - Brasil

E-mail: michelilunardi01@gmail.com

Telefone: (47) 3321-0565

\section{Larissa Degenhart}

Doutora em Ciências Contábeis e Administração pelo Programa de Pós-Graduação em

Ciências Contábeis da Universidade Regional de Blumenau (PPGCC/FURB)

Endereço: Rua Antônio da Veiga, $\mathrm{n}^{\circ}$ 140, Bairro Victor Konder

CEP 89012-900 - Blumenau/SC - Brasil

E-mail: lari_ipo@hotmail.com

Telefone: (47) 3321-0565

\section{Vinicius Costa da Silva Zonatto}

Pós-doutor em Ciências Contábeis (UNISINOS)

Doutor em Ciências Contábeis e Administração (FURB)

Professor do Programa de Pós-Graduação em Ciências Contábeis da Universidade Regional de Blumenau (PPGCC/FURB)

Endereço: Rua Antônio da Veiga, $n^{\circ}$ 140, Bairro Victor Konder

CEP 89012-900 - Blumenau/SC - Brasil

E-mail: viniciuszonatto@gmail.com

Telefone: (47) 3321-0565

Artigo recebido em 20/10/2017. Revisado por pares em 23/04/2018. Reformulado em 12/05/2018. Recomendado para publicação em 25/08/2018 por Carlos Eduardo Facin Lavarda (Editor-Chefe). Publicado em 31/03/2019. 


\section{Resumo}

Este estudo investiga os motivos pelos quais superiores incentivam a participação do subordinado nos processos orçamentários de empresas industriais sediadas no Brasil, mediante análise dos efeitos de antecedentes a participação orçamentária: estilo de liderança, assimetria da informação e uso avaliativo do orçamento. Pesquisa descritiva foi realizada mediante levantamento, com aplicação de questionário em amostra de 106 gerentes, analistas, coordenadores de orçamento ou controllers, e análise quantitativa dos dados, com auxílio de Modelagem de Equações Estruturais. Os resultados revelaram que superiores encorajam a participação dos subordinados quando o estilo de liderança do superior é considerado. Os motivos pelos quais os superiores incentivam esta participação estão relacionados a: obtenção de informações privadas de conhecimento de gestores subordinados; e, definição de objetivos e metas orçamentárias para avaliação de desempenho. Nem todos os antecedentes testados foram confirmados no contexto de atuação das empresas sediadas no Brasil, o que abre perspectivas a realização de novos estudos sobre o tema. Concluiu-se que estilo de liderança, uso avaliativo do orçamento e incentivo a participação orçamentária constituem-se antecedentes a participação dos gestores subordinados nos processos orçamentários de suas organizações. Estes achados permitem compreender o papel do líder nas organizações, a importância da utilização de metas orçamentárias para avaliação de desempenho dos subordinados e o incentivo à participação como recurso para qualificação dos processos orçamentários.

Palavras-chave: Estilo de liderança; Assimetria de informação; Uso avaliativo do orçamento; Participação orçamentária

\section{Abstract}

This study investigates the reasons why superiors encourage the participation of the subordinate in the budget processes of industrial companies headquartered in Brazil, through analysis of the antecedent effects of budget participation: leadership style, asymmetry of information and evaluation use of the budget. Descriptive research was carried out by means of a survey, with the application of a questionnaire in a sample of 106 managers, analysts, budget coordinators or controllers, and quantitative data analysis, with the aid of Modeling Structural Equations. The results revealed that superiors encourage subordinate participation when the superior's leadership style is considered. The reasons why the superiors encourage this participation are related to obtaining private information of knowledge of subordinate managers; and, the definition of objectives and budgetary targets for performance evaluation. Not all the antecedents tested were confirmed in the context of the performance of the companies headquartered in Brazil, which opens the prospect of new studies on the subject. It was concluded that leadership style, evaluative use of the budget and incentive to budget participation constitute antecedent the participation of subordinate managers in the budgetary processes of their organizations. These findings allow us to understand the role of the leader in organizations, the importance of using budget targets to evaluate the performance of subordinates, and encouraging participation as a resource for the qualification of budget processes.

Keywords: Leadership style; Asymmetry of information; Evaluative use of the budget; Budgetary participation

\section{Resumen}

Este estudio investiga los motivos por los cuales superiores incentivan la participación del subordinado en los procesos presupuestarios de empresas industriales con sede en Brasil, mediante análisis de los efectos de antecedentes a la participación presupuestaria: estilo de 
liderazgo, asimetría de la información y uso evaluativo del presupuesto. La investigación descriptiva fue realizada mediante levantamiento, con aplicación de cuestionario en muestra de 106 gerentes, analistas, coordinadores de presupuesto o controllers, y análisis cuantitativo de los datos, con ayuda de Modelado de Ecuaciones estructurales. Los resultados revelaron que los superiores alientan la participación de los subordinados cuando se considera el estilo de liderazgo del superior. Los motivos por los cuales los superiores incentivan esta participación están relacionados con: obtención de informaciones privadas de conocimiento de gestores subordinados; y la definición de objetivos y metas presupuestarias para la evaluación del desempeño. No todos los antecedentes probados fueron confirmados en el contexto de actuación de las empresas con sede en Brasil, lo que abre perspectivas a la realización de nuevos estudios sobre el tema. Se concluyó que estilo de liderazgo, uso evaluativo del presupuesto e incentivo a la participación presupuestaria se constituyen antecedentes la participación de los gestores subordinados en los procesos presupuestarios de sus organizaciones. Estos hallazgos permiten comprender el papel del líder en las organizaciones, la importancia de la utilización de metas presupuestarias para evaluación de desempeño de los subordinados y el incentivo a la participación como recurso para la calificación de los procesos presupuestarios.

Palabras clave: Estilo de liderazgo; Asimetría de información; Uso evaluativo del presupuesto; Participación presupuestaria

\section{Introdução}

O orçamento é considerado um dos temas mais pesquisados em contabilidade gerencial e tem sido estudado a partir de perspectivas teóricas da economia, psicologia e sociologia (COVALESKI et al. 2007). A abordagem comportamental na contabilidade é a mais utilizada a partir da realização de estudos enfatizando principalmente as perspectivas teóricas da psicologia (BIRNBERG; LUFT; SHIELDS, 2007). Esta abordagem comportamental na contabilidade visa avaliar as relações entre o uso de instrumentos de controle gerencial e seus efeitos sobre o comportamento dos indivíduos no trabalho (BIRNBERG; LUFT; SHIELDS, 2007; BALDVINSDOTTIR; MITCHELL; NORREKLIT, 2010).

Isto ocorre porque o comportamento contábil envolve a interação de pessoas e técnicas contábeis. Birnberg, Luft e Shields (2007) explicam que teorias da psicologia provaram ser úteis na pesquisa em contabilidade gerencial. Neste sentido, conforme destacam Kyj e Parker (2008), estudos na literatura de contabilidade têm examinado o uso do orçamento como um padrão para avaliar o desempenho dos subordinados, visto que as ações dos indivíduos tendem a afetar o desempenho da empresa.

O orçamento empresarial é considerado um importante instrumento de controle gerencial utilizado pelas organizações para os mais diversos fins, como por exemplo, o planejamento operacional, a coordenação das atividades, destinação de recursos, avaliação de desempenho, entre outros (HANSEN; VAN DER STEDE, 2004; COVALESKI et al., 2007). Além disso, o orçamento pode servir como instrumento para a motivação dos subordinados (BIRNBERG; LUFT; SHIELDS, 2007; COVALESKI et al., 2007; DERFUSS, 2016; DANI; ZONATTO; DIEHL, 2017), a partir da participação dos indivíduos nos processos orçamentários.

A participação orçamentária é definida como um processo administrativo no qual um subordinado está envolvido com seus supervisores, exercendo influência sobre a determinação e a realização do orçamento de sua unidade (SHIELDS; SHIELDS, 1998; SHIELDS; DENG; KATO, 2000; COVALESKI et al., 2007). Diferentes estudos têm sido desenvolvidos procurando investigar os efeitos da participação sobre o desempenho gerencial (DERFUSS, 
2016; DANI; ZONATTO; DIEHL, 2017). No entanto, a investigação de antecedentes a participação orçamentária necessita ser melhor explorada por pesquisadores da área comportamental da contabilidade (KYJ; PARKER, 2008), visto que na contemporaneidade, ainda existem dúvidas sobre os antecedentes que explicam porque as organizações utilizam a participação orçamentária, como também quais os fatores que impulsionam o uso da participação orçamentária, sendo esta a proposta de pesquisa da meta análise desenvolvida por Mahlendorf, Schaffer e Skiba (2015), o que se constitui uma oportunidade para a realização de novos estudos.

Além disso, Derfuss (2015) aborda que os resultados existentes sobre como as variáveis de contexto (antecedentes à participação orçamentária) se relacionam com a participação orçamentária são contraditórios. Entende-se que são os antecedentes a participação que determinam a configuração orçamentária participativa e seus efeitos cognitivos, motivacionais e de valor de realização, que impactarão positiva ou negativamente no desempenho gerencial.

Um dos elementos apontados como potencial antecedente a participação orçamentária é o estilo de liderança. O tema liderança tem uma forte utilização tanto para os dirigentes como para as pessoas que são dirigidas na organização (BERGAMINI, 1994). Ao longo da existência humana, o homem sempre se encontrou sujeito às influências de outros indivíduos dos quais interagia e devido a essas interações e da necessidade de encontrar soluções conjuntas que gerassem a sobrevivência do grupo ou da comunidade, surgiu a necessidade de liderança (BERGAMINI, 1994; SOBRAL; GIMBA, 2012). A realidade das organizações comprova uma ligação entre a personalidade dos administradores e líderes e o tipo de administração das empresas, visto que a individualidade dos dirigentes é útil para uma melhor compreensão dos fenômenos relacionados à administração e à liderança (LAPIERRE, 1989).

Nesse sentido, estudos sobre comportamentos dos líderes e de seus subordinados são cada vez mais importantes nos mais variados contextos (SOBRAL; GIMBA, 2012; RENKO; TARABISHY; BRANNBACK, 2013). Na área de estudos da contabilidade comportamental, o estilo de liderança tem sido investigado no contexto orçamentário, analisando a sua influência sobre as ações de seus subordinados, bem como o seu desempenho no trabalho (KYJ; PARKER, 2008). Popli e Rizvi (2016) comentam que o estilo de liderança necessita ser promovido nas organizações, com vistas a incentivar o desempenho do colaborador. Portanto, torna-se oportuno analisar o estilo de liderança como um dos antecedentes da participação do indivíduo nos processos orçamentários das organizações, uma vez que o líder é o gestor responsável por incentivar a participação de seus subordinados no processo orçamentário ou inibi-lo.

Contudo, o estilo de liderança pode causar conflitos nas empresas entre superiores e seus subordinados, pois conforme Baiman (1990) e Faria et al. (2011) os administradores muitas vezes possuem objetivos pessoais divergentes para a maximização da riqueza dos acionistas e passam a agir e decidir conforme seus interesses próprios em detrimento do melhor benefício aos acionistas. Quando isto ocorre, geram-se conflitos de agência, que elevam os níveis de assimetria de informação, podendo afetar negativamente o desempenho dos gestores no trabalho (KYJ; PARKER, 2008; ZONATTO; LAVARDA, 2013; LAVARDA; ALMEIDA, 2013).

Baiman (1990) e Faria et al. (2011) destacam que a assimetria de informação poderá surgir a partir do momento que forem delegadas competências em relação a tomada de decisão aos colaboradores da organização. Deste modo, a existência de assimetria de informação pode criar problemas de controle para os proprietários, uma vez que se estes usarem as informações privadas da organização para tomar decisões para seus próprios interesses e não considerarem os interesses dos próprios proprietários, poderá haver prejuízos a organização (PENNO, 1984).

No que tange ao processo orçamentário, Lavarda e Almeida (2013) salientam que a assimetria de informação pode ocorrer nas organizações, pois o planejamento, a execução e o 
controle dos objetivos da empresa estão sujeitos à ação dos gestores e estes poderão ter maiores informações, quando as metas instituídas na organização são atribuídas pelos superiores sem participação de todos os envolvidos. Evidências encontradas por Zonatto e Lavarda (2013) têm sugerido que a participação do indivíduo nos processos orçamentários relaciona-se com a redução dos níveis de assimetria informacional e estresse ocupacional, impactando positivamente o desempenho dos indivíduos no trabalho.

Contudo, tais resultados não são observados em todas as organizações. Segundo Kyj e Parker (2008), estudos na literatura de contabilidade comportamental têm sugerido que outras variáveis intervenientes antecedem a participação orçamentária, como a assimetria de informação, o estilo de liderança e o uso avaliativo do orçamento, as quais são capazes de influenciar a forma como os indivíduos participarão dos processos orçamentários. Por esta razão, estes autores destacam que a assimetria de informação, o estilo de liderança e o uso avaliativo do orçamento se constituem elementos motivadores para a participação do indivíduo nos processos orçamentários, ou seja, antecedentes a participação orçamentária.

Apesar da assimetria ter sido tratada como um antecedente da participação em diversos estudos, como Pope (1984), Shields e Young (1993), Shields e Shields (1998), Fisher, Frederickson e Peffer (2002) e Kyj e Parker (2008) ou ter sua relação com a participação investigada nos trabalhos de Christensen (1982), Baiman e Evans (1983), Penno (1984), Young (1985), Dunk (1993), Lavarda e Almeida (2013), Zonatto e Lavarda (2013) e Buzzi et al. (2014), os resultados sobre esta relação têm sido conflitantes e inconclusivos. No contexto brasileiro, enquanto Zonatto e Lavarda (2013) encontraram uma relação negativa entre participação orçamentária e assimetria de informação, Lavarda e Almeida (2013) encontraram evidências opostas, indicando que a participação orçamentária não foi suficiente para reduzir os níveis de assimetria informacional naquele estudo.

Em relação ao estilo de liderança e o uso avaliativo do orçamento, as evidências encontradas em estudos anteriores sugerem que estas variáveis se constituem determinantes chave em tal relação (FLEISHMAN; HARRIS, 1962; VALENZI; DESSLER, 1978; OTLEY; PIERCE, 1995; BARTOLO; FURLONGER, 2000; KYJ; PARKER, 2008; NIEMEYER; CAVAZOTTE, 2016; POPLI; RIZVI, 2016). Neste contexto, pode-se inferir que talvez a assimetria de informação possa não se constituir um elemento antecedente a participação dos indivíduos nos processos orçamentários, mas sim um elemento presente neste contexto, que poderá ou não ter seus efeitos negativos mitigados, em função do nível de participação dos indivíduos nestes processos. Tal pressuposto permite testar a assimetria como um elemento consequente a participação orçamentária, modificando-se o modelo teórico de análise proposto por Kyj e Parker (2008).

Diante do exposto, uma oportunidade de pesquisa identificada nesta temática, refere-se à necessidade de se avaliar junto a empresas industriais sediadas no Brasil os efeitos de antecedentes da participação orçamentária (assimetria de informação, estilo de liderança e o uso avaliativo do orçamento), no que tange a relação de superiores e seus subordinados, de modo a se compreender os fatores que incentivam os indivíduos a participação em tais processos. Do mesmo modo, torna-se oportuno avaliar os efeitos específicos da participação orçamentária na assimetria de informação, observada não como um elemento antecedente a participação, mas como uma variável presente no contexto orçamentário destas organizações.

Neste sentido, considerando-se a lacuna de pesquisa identificada na literatura, que versa sobre os resultados conflitantes encontrados em estudos anteriores que investigaram tais relacionamentos, questiona-se: Quais fatores (motivos) constituem-se antecedentes da participação de gestores subordinados nos processos orçamentários de organizações industriais sediadas no Brasil? Com o intuito de responder à questão apresentada, o objetivo desta pesquisa consiste em verificar os motivos pelos quais os superiores incentivam a participação do 
subordinado nos processos orçamentários de empresas industriais sediadas no Brasil, a partir da análise dos efeitos de antecedentes a participação (estilo de liderança, assimetria da informação e uso avaliativo do orçamento).

Justifica-se a escolha destes antecedentes à participação orçamentária, pois os superiores incentivam a participação dos subordinados no processo orçamentário com vistas a promover melhores relações com os subordinados e assim, expressam o seu estilo de liderança (ARGYRIS, 1952; KYJ; PARKER, 2008). Além disso, os superiores incentivam os subordinados para participarem das atividades orçamentárias, com o intuito de obter informações privadas dos subordinados, promovendo o compartilhamento de informação (SHIELDS; YOUNG, 1993; SHIELDS; SHIELDS, 1998; KYJ; PARKER, 2008; CHAPMAN; KIHN, 2009), o que visa minimizar a assimetria de informação entre superior e subordinado. Por fim, optou-se ainda pelo antecedente à participação orçamentária uso avaliativo do orçamento, pois os subordinados procuram se envolver e participar dos processos orçamentários quando isto implica na sua avaliação de desempenho. Assim, quando as metas orçamentárias são utilizadas para avaliar os subordinados, os superiores tendem a incentivar mais a participação e o envolvimento dos subordinados na definição do orçamento (LAU; BUCKLAND, 2000; 2001; LAU; TAN, 2003; KYJ; PARKER, 2008).

A liderança nas organizações (VIZEU, 2011) é um tema emergente, visto que o estilo de liderança dos gestores tende a apresentar efeitos sobre as atitudes e comportamentos dos subordinados no trabalho, tema relevante para acadêmicos e profissionais (MULKI; CAEMMERER; HEGGDE, 2015). Um estilo de liderança apropriado é uma estratégia determinante para a participação de gestores em processos orçamentários (KYJ; PARKER, 2008), bem como para que as empresas possam alcançar a inovação e competitividade (VARGAS, 2015). O uso do orçamento para fins de avaliação de desempenho também tende a influenciar o comportamento dos gestores no trabalho, razão pela qual seus efeitos precisam ser observados. Da mesma forma, a compreensão sobre a existência de assimetria informacional e seus eventuais efeitos no contexto orçamentário, constitui-se um importante elemento de análise neste campo de estudos. Assim, esta pesquisa busca proporcionar a partir dos seus resultados, implicações importantes para a literatura contábil, relacionada a pesquisa comportamental e gerencial.

Nesse sentido, ao explorar os motivos pelos quais os superiores incentivam a participação orçamentária, os pesquisadores, bem como gestores, podem entender melhor as causas da participação orçamentária nas organizações e, consequentemente, como a participação afeta os resultados no local de trabalho, tais como o desempenho dos indivíduos nas atividades orçamentárias, sendo esta uma implicação prática desta pesquisa. Além disso, a controladoria é considerada uma área geradora de informações, o que possibilita minimizar os níveis de assimetria de informação, sendo os gestores com responsabilidades orçamentárias, os indivíduos que viabilizam o atingimento dos objetivos da empresa.

Deste modo, os resultados produzidos nesta pesquisa permitem a compreensão do papel do líder nas organizações, por meio do seu estilo de liderança, da importância do compartilhamento de informações com vistas a redução da assimetria de informação entre superior e seus subordinados, e pela relevância da utilização de metas orçamentárias para a avaliação do desempenho dos subordinados, visto que assim estes indivíduos apresentarão maior envolvimento para o atingimento destas metas. Os achados deste estudo permitem uma reflexão sobre o direcionamento de maiores esforços nas organizações para a participação dos subordinados nos processos orçamentários, visto sua influência para a diminuição dos níveis de assimetria de informação. A pesquisa contribui ainda para o avanço dos estudos que buscam investigar antecedentes a participação orçamentária, distinguindo-se da proposta apresentada e testada por Kyj e Parker (2008). 
No que tange as contribuições práticas e sociais deste estudo, destaca-se que ao evidenciar no cenário brasileiro os antecedentes à participação orçamentária e seus efeitos na participação dos indivíduos nos processos orçamentários, esta pesquisa contribui com a identificação das práticas de gestão orçamentária adotadas no País e alguns de seus condicionantes. Além disto, permite as organizações avaliarem suas práticas de gestão, bem como reforçar os aspectos de liderança nos superiores, com o intuito de estabelecer planos de capacitação e treinamento extensivos a superiores e subordinados, com vistas a alcançar melhor desempenho dos indivíduos nos processos orçamentários, o desempenho da organização, em face a redução dos níveis de assimetria informacional e o alcance de objetivos e metas orçamentárias estabelecidas. Estes achados servem ainda a outras empresas não analisadas nesta amostra, por permitir a identificação de fatores que interferem na configuração orçamentária participativa e seus efeitos consequentes na assimetria de informação, visto que em determinado nível, a participação orçamentária pode apresentar influência positiva para o equilíbrio da informação entre superior e seus subordinados.

\section{Modelos Teóricos de Análise e Hipóteses de Pesquisa}

Este capítulo apresenta os modelos teóricos de análise investigados e as hipóteses de pesquisa. Ressalta-se que as hipóteses de pesquisa $\mathrm{H}_{1}, \mathrm{H}_{2}$ e $\mathrm{H}_{3}$, foram elaboradas a partir do estudo de Kyj e Parker (2008). Além disso, as hipóteses de pesquisa $\mathrm{H}_{4 a}$ e $\mathrm{H}_{4 b}$ foram desenvolvidas para serem testadas no modelo teórico concorrente ao de Kyj e Parker (2008), contribuição desta pesquisa, pois buscou-se aprimorar o modelo teórico de análise proposto por estes autores no cenário brasileiro.

\subsection{Estilo de Liderança no Contexto Orçamentário}

A Teoria da Liderança concentra-se em explicar o estilo de liderança dos gestores, visto que os recursos humanos são considerados fatores centrais nas organizações (KASIATI; MINARSIH; WARSO, 2015). Neste sentido, uma importante área de pesquisa envolve o estudo da relação entre os subordinados e supervisores, sendo este tópico também relacionado à liderança (PRATT; JIAMBALVO, 1982). Conforme Yukl (1989), o estudo da liderança tem sido uma parte importante da literatura sobre gestão e comportamento organizacional por várias décadas. Devido à sua complexidade e relevância para as empresas, entender a liderança, apresentada como a capacidade de influenciar as pessoas de modo a alcançar metas e objetivos, tem sido um dos temas mais desafiadores e controversos para os pesquisadores da área de estudos organizacionais (SOBRAL; GIMBA, 2012).

Otley e Pierce (1995) salientam que o estilo de liderança inicialmente tem recebido considerável atenção na área da psicologia industrial e na literatura sobre controle gerencial e contabilidade. O estilo de liderança dos gestores pode ser uma variável importante para a compreensão da influência dos sistemas de controle formal sobre o comportamento individual (OTLEY; PIERCE, 1995). De acordo com Fleishman (1953), há uma preocupação nas empresas para com os problemas de liderança e relações humanas e esta preocupação pode ser vista como tentativas de modificar ou até mesmo melhorar o comportamento dos supervisores em lidar com os seus subordinados nas relações de trabalho (HARRIS; FLEISHMAN, 1955).

$\mathrm{Na}$ literatura é possível identificar pesquisas que buscaram uma definição para a liderança (ALMADA; POLICARPO, 2016). Para Fleishman (1953), a liderança eficaz depende da situação vivenciada. Já para Pratt e Jiambalvo (1981) pode ser determinada por meio da análise do processo pelo qual os comportamentos do líder afetam o desempenho dos subordinados. Para tanto, o comportamento do líder relaciona-se com a eficácia do trabalho em 
equipe, visto que este se relaciona com a alta satisfação dos funcionários com o seu supervisor e colegas de trabalho (BARTOLO; FURLONGER, 2000).

A maioria das definições sobre liderança envolve um processo de influência (YUKL, 1989; RENKO, TARABISHY; BRANNBACK, 2013) e a formação e o treinamento dos superiores que de algum modo afeta a liderança praticada no grupo de trabalho (HARRIS; FLEISHMAN, 1955). Fleishman e Harris (1962) ressaltam a partir de seus estudos que existem relações significativas entre o comportamento do líder e seus subordinados, e que a consideração do líder e seus subordinados estão associados com a satisfação no trabalho dos subordinados (VALENZI; DESSLER, 1978).

Diversos estudos foram desenvolvidos com vistas a examinar o papel do estilo de liderança nas empresas (PRATT; JIAMBALVO, 1981; 1982; KIDA, 1984; OTLEY; PIERCE, 1995), bem como os efeitos do estilo de liderança e da participação orçamentária no desempenho e satisfação no trabalho (BROWNELL, 1983; ADLER; REID, 2008). Também há estudos desenvolvidos sobre o comportamento de liderança e satisfação no trabalho (BARTOLO; FURLONGER, 2000), a influência da liderança ética na relação entre líderes e subordinados (NIEMEYER; CAVAZOTTE, 2016), o efeito do estilo de liderança, da comunicação interna e da cultura organizacional sobre o desempenho do empregado (KASIATI; MINARSIH; WARSO, 2015) e os estilos de liderança e o envolvimento dos funcionários (POPLI; RIZVL, 2016).

Apesar disto, ainda são poucos os estudos que analisaram o estilo de liderança e a participação no orçamento. Conforme Brownell (1983), sob certas condições de liderança, a participação orçamentária apresenta efeitos positivos sobre o desempenho e a satisfação no trabalho. No entanto, sob outras condições, o contrário também pode vir a ocorrer. No estudo desenvolvido pelo autor os resultados indicaram a existência de ambas as relações entre o estilo de liderança e a participação no orçamento. Brownell (1983) destaca ainda que o estilo de liderança é uma variável que precisa ser incluída em investigações relacionadas ao contexto orçamentário, visto que é importante para a compreensão das relações existentes neste contexto, pois os superiores tendem a usar os orçamentos como um meio de expressar seu estilo de liderança. Outra variável a ser observada é a extensão da participação em atividades relacionadas com o orçamento nas empresas.

Frente esta relação dos estilos de liderança e a participação orçamentária, pesquisadores da área de comportamento organizacional tem colocado uma ênfase crescente em analisar modelos de mediação em que a influência de um antecedente é transmitida a uma consequência, por meio da intervenção de um mediador (JAMES; BRETT, 1984). Esta pesquisa propõe que o estilo de liderança é um antecedente da participação no orçamento de organizações industriais sediadas no Brasil, e assim, que o incentivo a participação orçamentária é uma variável que medeia a relação entre o estilo de liderança e a participação orçamentária, visto que as avaliações de desempenho exercem um papel crucial em uma variedade de decisões pessoais (KIDA, 1984).

$\mathrm{Na}$ área contábil, a literatura de controle de gestão tem evidenciado casos de comportamentos dos indivíduos que foram ligados ao sistema de controle, visto que o comportamento de liderança do supervisor pode influenciar o desempenho do subordinado (OTLEY; PIERCE, 1995). Bartolo e Furlonger (2000) destacam que a relação entre o estilo de liderança e a satisfação no trabalho é um indicador de interação entre o supervisor e seu subordinado. Mulki, Caemmerer e Heggde (2015) ressaltam que cada estilo de liderança estabelece normas diferentes em relação às expectativas e comportamentos dos funcionários. Assim, a qualidade da liderança apresenta uma associação direta com a qualidade da relação entre os membros da organização, com base em categorias de confiança pessoal e profissional (ZANINI; SANTOS; LIMA, 2015). 
Com base nestas evidências, de que os gestores são suscetíveis de incentivarem os subordinados a participarem durante o processo orçamentário da organização, desenvolveu-se a seguinte hipótese de pesquisa: H1: O estilo de liderança do superior apresenta uma relação positiva com o incentivo do superior à participação do orçamento. Assim sendo, quando os superiores promovem a participação dos subordinados no orçamento, estes são mais propensos a participarem, o que oferece suporte teórico a segunda hipótese elaborada para o estudo: $\mathbf{H}_{2}$ : $\mathrm{O}$ incentivo do superior na participação do orçamento está positivamente relacionado com a participação no orçamento pelo subordinado.

Depreende-se que o estilo de liderança é cada vez mais importante em uma variedade de contextos, visto que nas empresas estes comportamentos promovem a inovação e adaptação em ambientes de mudança (RENKO, TARABISHY; BRANNBACK, 2013). Além disso, os recursos das empresas se não forem gerenciados adequadamente, não irão arcar com o planejado, sendo o papel do líder muito importante, utilizando sua autoridade e liderança para conduzir seus subordinados de modo que se possa alcançar os objetivos organizacionais préestabelecidos (KASIATI; MINARSIH; WARSO, 2015).

Portanto, estilos de liderança e práticas de recursos humanos impulsionam o envolvimento dos subordinados e necessitam ser promovidos nas organizações para impulsionar o desempenho. No ambiente contemporâneo de aumento da concorrência, o envolvimento dos funcionários é visto como uma estratégia chave para o sucesso organizacional (POPLI; RIZVL, 2016). Nesse ponto, espera-se que a participação do subordinado na elaboração do orçamento possibilite diminuir a assimetria da informação existente entre superiores e seus subordinados, temática apresentada na sequência.

\subsection{Assimetria de Informação no Contexto Orçamentário}

Os orçamentos são utilizados para a realização de planejamento, coordenação, avaliação e controle nas empresas (ADLER; REID, 2008). São resultados de um processo de negociação importante para entender como a assimetria de informação afeta esse processo (FISHER; FREDERICKSON; PEFFER, 2002). Pope (1984) destaca que existe literatura com o intuito de estabelecer evidências sobre os efeitos da participação gerencial na definição do orçamento, sendo um destes efeitos a assimetria informacional. Em ambientes com informação assimétrica, eficiência é definida com relação à informação completa ou simétrica. Este cenário seria o ideal, se todos os superiores possuíssem informações completas sobre as reais preferências dos subordinados (HARRIS; TOWNSEND, 1981).

Conforme Christensen (1982) é importante os subordinados participarem na determinação de seus padrões de desempenho, visto que a participação é usada para transmitir informações de um subordinado melhor informado para um supervisor menos informado. A avaliação de desempenho e motivação do subordinado é uma questão a ser analisada na literatura contábil. Muitos procedimentos de controle gerencial utilizados nas empresas envolvem a participação, tais como, o orçamento, a gestão por objetivos e a definição de normas participativas. Estes procedimentos permitem que o subordinado negocie procedimentos com o superior e nesse ambiente participativo cada indivíduo escolha a sua estratégia com base em sua informação (BAIMAN; EVANS, 1983; PENNO, 1984; YOUNG, 1985). Em organizações que o subordinado tem melhor informação do que o superior, um sistema de controle gerencial baseado na participação permite que o subordinado revele informações privadas, que podem ser incorporadas no processo de orçamento, reduzindo a assimetria (BAIMAN; EVANS, 1983; PENNO, 1984; POPE, 1984; YOUNG, 1985).

Uma das dificuldades neste processo é que o subordinado pode não repassar toda a informação aos supervisores, o que pode ocasionar um orçamento menos eficiente do que o 
orçamento que teria sido acordado se a informação privada do subordinado era do conhecimento do superior. Um sistema relevante neste contexto seria o orçamento participativo (BAIMAN; EVANS, 1983; PENNO, 1984; POPE 1984; YOUNG, 1985), uma vez que este poderia facilitar a troca de informações entre os participantes deste processo.

Os proprietários podem buscar reduzir esse problema por meio da implantação de um sistema de controle gerencial que diminua essa assimetria informacional (PENNO, 1984). Contudo, Hopwood (1976) salienta que o orçamento é visto em termos muito mais amplos do que uma técnica e procedimento, mas sim como parte de um processo que é influenciado por atitudes e comportamentos gerenciais dos funcionários. A necessidade de envolvimento, o compromisso e a participação dos subordinados em definir os orçamentos é vital nas organizações e a comunicação da informação proporciona um equilíbrio orçamentário. Neste sentido, a literatura comportamental da área contábil reconhece que a assimetria de informação no desenvolvimento de orçamentos é importante (POPE, 1984).

Apesar disso, estabelecer um orçamento pode ser um problema quando os subordinados possuem melhor informação do que um superior sobre os fatores que influenciam o desempenho (CHOW; COOPER; WALLER, 1988). Cada indivíduo age com base em suas preferências e crenças, sendo comum a suposição da assimetria de informação (BAIMAN, 1990). Shields e Young (1993) destacam que uma revisão de estudos empíricos sobre a participação orçamentária indicou que a maioria das pesquisas realizadas até então foca sobre as suas consequências (atitude, motivação, desempenho, satisfação), ao invés de analisar os antecedentes, como é o caso desta pesquisa. Contudo, estes autores contemplam a investigação da assimetria de informação como um elemento que antecede a participação dos indivíduos nos processos orçamentários de suas organizações.

Os resultados do estudo de Shields e Young (1993) revelaram que a participação orçamentária é mais importante para o planejamento e controle e o compartilhamento de informações entre subordinados e superiores, razões estas para a existência de um modelo de orçamento participativo (SHIELDS; SHIELDS, 1998). Os achados da pesquisa de Fisher, Frederickson e Peffer (2002) indicaram que a assimetria de informação afeta o processo de negociação, o nível de folga orçamental e a diferença informacional entre superiores e subordinados.

Lavarda e Almeida (2013) encontraram evidências em seu estudo que as empresas analisadas, mesmo com um modelo de orçamento participativo, não minimizaram a assimetria informacional, visto que a maioria das respostas se concentrou em um único item: que o gestor/subordinado possui mais informações do que seu gerente/superior. Já os resultados do estudo desenvolvido por Zonatto e Lavarda (2013) indicaram que empresas que possuem uma configuração orçamentária participativa, reduzem os níveis de assimetria de informação e estresse no trabalho. Estes autores concluem que a participação orçamentária pode reduzir os níveis de assimetria informacional e estresse ocupacional, o que influencia positivamente o desempenho no trabalho, uma vez que essa configuração permite aos envolvidos discutir a alocação de recursos, objetivos e metas orçamentárias, de modo a elaborar um orçamento mais real e adequado a realidade da organização, considerando-se as diferentes necessidades das unidades divisionais. Estes resultados apresentam implicações para os processos orçamentários, visto que a informação pode apresentar grandes efeitos sobre os orçamentos e consequências econômicas (FISHER; FREDERICKSON; PEFFER, 2002).

A partir de uma análise comparativa dos resultados encontrados em alguns estudos que analisaram os efeitos da assimetria de informação no contexto orçamentário, como Christensen (1982), Baiman e Evans (1983), Penno (1984), Pope (1984), Young (1985), Dunk (1993), Shields e Young (1993), Shields e Shields (1998), Fisher, Frederickson e Peffer (2002), Faria et al. (2011), Lavarda e Almeida (2013), Zonatto e Lavarda (2013) e Buzzi et al. (2014), pôde- 
se verificar que esta relação também apresenta resultados conflitantes, o que estimula a realização de novas investigações.

Assim, para a realização deste estudo, os efeitos da assimetria informacional no contexto orçamentário serão investigados de duas formas. No primeiro modelo teórico de análise, a assimetria informacional é considerada um antecedente da participação orçamentária, visto que a participação pode ser um mediador entre assimetria e resultados da informação, tais como folga orçamental e o desempenho no trabalho (CHOW; COOPER; WALLER, 1988). Logo, constitui-se uma motivação para o incentivo dos gestores a participação nos processos orçamentárias das empresas em que atuam. Neste sentido, assim como proposto por Kyj e Parker (2008), a terceira hipótese do estudo versa sobre: H3: A assimetria da informação apresenta uma relação positiva com o incentivo do superior na participação do orçamento.

Shields e Shields (1998) ressaltam que os modelos teóricos sobre a assimetria da informação apresentam uma relação antecedente com a participação orçamentária, pois a demanda deste orçamento é causada pela incerteza do ambiente. Assim, na existência deste tipo de orçamento (inclusivo), o compartilhamento de informações internas está previsto para ser associado com a assimetria da informação. Por outro lado, há evidências que sugerem que apenas a participação dos indivíduos nos processos orçamentários pode não ser suficiente para estimular os gestores a socializarem informações.

Apesar de tais evidências, Kyj e Parker (2008) ao abordarem a assimetria de informação como um dos elementos motivadores para a participação do indivíduo nos processos orçamentários, não encontraram relação significativa entre estas variáveis. Diversos estudos que analisaram a assimetria de informação como um fator antecedente da participação orçamentária, tais como Pope (1984), Shields e Young (1993), Shields e Shields (1998), Fisher, Frederickson e Peffer (2002) e Kyj e Parker (2008), tem apresentado resultados conflitantes e inconclusivos sobre esta relação.

As pesquisas de Shields e Young (1993) e Dunk (1993) encontraram uma relação significativa entre a assimetria da informação e a participação orçamentária, o que sugere que a assimetria pode ser um fator antecedente à participação. Shields e Shields (1998), Kyj e Parker (2008) e Jermias e Yigit (2013) não encontraram relação significativa entre estas variáveis. Logo, estes resultados revelam que a assimetria da informação pode não se constituir um fator antecedente da participação orçamentária, mas sim um elemento presente no processo orçamentário, que poderá ou não ser mitigado pelos níveis de participação orçamentária (SHIELDS; SHIELDS, 1998; KYJ; PARKER, 2008; JERMIAS; YIGIT, 2013; DERFUSS, 2016).

Assim, considerando-se que a assimetria informacional pode não se constituir um elemento motivador (antecedente) a participação de gestores de organizações industriais sediadas no Brasil no processo orçamentário, estabeleceu-se um segundo modelo teórico de análise para esta pesquisa. Neste caso, parte-se da premissa que a assimetria informacional é um elemento natural existente nos processos orçamentários, os quais podem ou não serem mitigados pela participação orçamentária. Desta forma, com vistas a verificar os efeitos da participação orçamentária sobre a assimetria informacional existente no contexto orçamentário, desenvolveu-se duas hipóteses adicionais de pesquisa $\left(\mathrm{H}_{4 \mathrm{a}}\right.$ e $\left.\mathrm{H}_{4 \mathrm{~b}}\right)$, as quais são testadas no segundo modelo teórico de investigação.

Inicialmente estabeleceu-se que há uma relação negativa entre a participação orçamentária e a assimetria informacional $\left(\mathbf{H}_{4}\right)$. A explicação para se analisar tal relação entre a participação orçamentária e a assimetria de informação, parte do pressuposto de que a participação dos indivíduos nos processos orçamentários visa a troca de informações (SHIELDS; YOUNG, 1993; DUNK, 1993; SHIELDS; SHIELDS, 1998; NOURI; PARKER, 1998; KYJ; PARKER, 2008; JERMIAS; YIGIT, 2013; DERFUSS, 2015), o que posteriormente 
pode reduzir os níveis de assimetria de informação.

De acordo com Shields e Young (1993), a assimetria de informação ocorre quando há um desequilíbrio informacional entre os superiores e os seus subordinados sobre os processos orçamentários. Deste modo, por meio da participação orçamentária é possível que os subordinados compartilhem mais informações com os seus superiores, o que consequentemente irá reduzir os níveis de assimetria de informação. Assim, conforme a assimetria de informação aumenta, haverá mais ganho potencial com a configuração participativa nos processos orçamentários (BROWNELL; HIRST, 1986; SHIELDS; YOUNG, 1993; JERMIAS; YIGIT, 2013; DERFUSS, 2015), a qual atuaria para a redução dos níveis de assimetria informacional existentes.

Neste caso, inserindo-se a assimetria de informação como uma variável consequente da participação orçamentária, presente neste contexto, podem-se encontrar evidências de resultados positivos e negativos, ou seja, que a participação orçamentária por si só não será capaz de reduzir os níveis de assimetria de informação (relação positiva) (DUNK, 1993; DOUGLAS; WIER, 2000; LAVARDA; ALMEIDA, 2013), ou ainda que a participação orçamentária é capaz de reduzir os níveis de assimetria informacional (relação negativa) (BROWNELL; HIRST, 1986; CHOW; COOPER; WALLER, 1988; FISHER; FREDERICKSON; PEFFER, 2002; KYJ; PARKER, 2008; ZONATTO; LAVARDA, 2013; MAHLENDORF; SCHAFFER; SKIBA, 2015), em condições em que os indivíduos participantes dos processos orçamentários percebem sua influência na definição dos objetivos e metas fixados, o que favorece a socialização de informações e a realização de ajustes nas previsões realizadas.

Conforme explica Jermias e Setiawan (2008), a alta gerência é muitas vezes relutante em compartilhar informações com os subordinados, pois teme que estes manipulem e interpretam mal essa informação, fazendo com que a participação orçamentária não seja capaz de minimizar de fato os níveis de assimetria informacional existentes entre superior e seus subordinados. Desta forma, há também que se reconhecer que tais efeitos poderão serem encontrados em organizações industriais sediadas no Brasil. Assim, a hipótese alternativa elaborada para o teste de tais relações versa sobre a existência de uma relação positiva entre a participação orçamentária e a assimetria informacional $\left(\mathbf{H}_{\mathbf{4 b}}\right)$, como relatado por Lavarda e Almeida (2013).

Diante do exposto, nota-se a relevância de se analisar um modelo alternativo para se investigar a relação existente entre a participação orçamentária e a assimetria de informação, visto que a assimetria não tem apresentado resultados conclusivos diante da participação orçamentária, especificamente em relação à identificação dos efeitos antecedentes da assimetria informacional na participação orçamentária, bem como dos efeitos consequentes da participação orçamentária em questões relacionadas a sua potencial capacidade para a redução dos níveis de assimetria informacional.

\subsection{Uso Avaliativo do Orçamento}

De acordo com Kyj e Parker (2008), outra variável utilizada para se investigar antecedentes a participação orçamentária, refere-se ao uso avaliativo do orçamento. De modo geral, duas correntes de pesquisa podem ser identificadas frente à relação entre o uso avaliativo e a participação no orçamento dos subordinados: estudos que apresentam uma ligação direta entre o uso avaliativo e a participação do orçamento, e pesquisas que não apresentam uma relação entre as temáticas. Harrison (1992) salienta que a participação, o uso avaliativo do orçamento e as atitudes dos subordinados, além do seu desempenho no trabalho são questões importantes que precisam ser consideradas nas pesquisas em contabilidade gerencial. 
A literatura relacionada ao orçamento sob a ótica da sociologia representa as práticas do orçamento participativo e a avaliação de desempenho baseada no orçamento e a compensação do subordinado como uma forma de simplificação organizacional na tomada de decisão e às vezes como parte da construção, funcionamento e a classificação das relações de poder em torno das organizações (COVALESKI et al., 2007). Além disso, os autores destacam que em quase todos os estudos sobre participação orçamentária, subordinados têm autoridade final sobre a criação do orçamento. Assim, sob uma perspectiva psicológica é pertinente se investigar os efeitos do uso avaliativo do orçamento como um antecedente a participação dos gestores subordinados nos processos orçamentárias das empresas, visto que, ao definir o uso do orçamento para avaliar o desempenho, esta definição exercerá influência sobre as cognições dos indivíduos no trabalho, bem como suas ações, comportamentos e o seu desempenho.

Shields e Shields (1998) indicam que a participação orçamentária possui importância para o planejamento e o controle dos processos gerenciais na organização. Conforme Brownel e Hirst (1986), a participação do subordinado no orçamento pode proporcionar a oportunidade para os gestores obterem acesso a recursos que podem ser usados para o desempenho da organização. Chow, Cooper e Waller (1988) explicam que o subordinado tem melhor informação para a elaboração do orçamento. Assim, mediante sua participação, pode-se haver planejamento do orçamento de tal modo que o subordinado pode preferir um orçamento igual ao seu desempenho esperado. Desta maneira, a participação orçamentária tem sido abordada como um meio pelo qual essa preferência pode ser expressa pelo subordinado.

Mia (1988) destaca que as atitudes gerenciais e a motivação do subordinado estão interligadas ao efeito da participação no orçamento e esta participação está associada com o melhor desempenho. Além disso, a participação no orçamento afeta o desempenho no trabalho por meio da adequação do orçamento e o comprometimento organizacional. A adequação do orçamento é o momento em que o subordinado percebe que os valores orçados são adequados para cumprir com as exigências do trabalho e, desta maneira, o subordinado poderá obter informações sobre o nível de apoio do orçamento para a realização das suas funções de trabalho (NOURI; PARKER, 1998).

Chong e Eggleton (2007) examinaram os efeitos da assimetria da informação e o comprometimento organizacional entre o grau de dependência da compensação baseada em incentivos e o desempenho gerencial dos gestores e subordinados. Os autores constataram que quanto maior o desempenho gerencial, menor é o comprometimento organizacional e alta é a dependência da compensação pelos incentivos, sendo também maior a assimetria da informação. Por sua vez, Parker e Kyj (2006) desenvolveram um modelo de partilha de informação vertical entre os superiores e subordinados no processo orçamentário, que auxilia a compreensão dos efeitos da participação dos gestores no orçamento, o seu comprometimento organizacional e o desempenho no trabalho.

Posteriormente Kyj e Parker (2008) exploraram os antecedentes da participação no orçamento, com vistas a entender o papel da participação no local de trabalho e buscaram verificar as razões pelas quais os superiores incentivam a participação no orçamento de seus subordinados. Para os autores a participação no orçamento pode mediar à relação entre o estilo de liderança e os resultados do trabalho. Além disso, os superiores incentivam a participação, quando as metas orçamentárias são utilizadas na avaliação de desempenho dos subordinados, caso em que o estudo argumenta que os superiores incentivam a participação por causa de preocupações sobre justiça organizacional.

Como pode-se verificar a partir das evidências relatadas, a participação no orçamento pode melhorar o desempenho dos gestores no trabalho. Contudo, seus efeitos dependem das condições de uso deste instrumento de controle gerencial para se avaliar o desempenho dos subordinados no trabalho. Nesse sentido, considerando-se que a participação orçamentária 
permite que um subordinado possa demostrar suas informações para a realização de suas tarefas e especificar os padrões de desempenho, podendo levar a uma maior satisfação no trabalho (YOUNG, 1985), é possível se admitir que quando o uso avaliativo do orçamento é realizado pelo superior, tem-se que os incentivos do superior a participação no orçamento sejam efetivados. Desta maneira, a quinta hipótese do estudo versa: H5: O uso avaliativo do orçamento apresenta uma relação positiva com o incentivo do superior à participação no orçamento.

A Figura 1 apresenta as relações investigadas nos dois modelos teóricos de análise estabelecidos para esta pesquisa.

Figura 1 - Modelos teóricos de análise

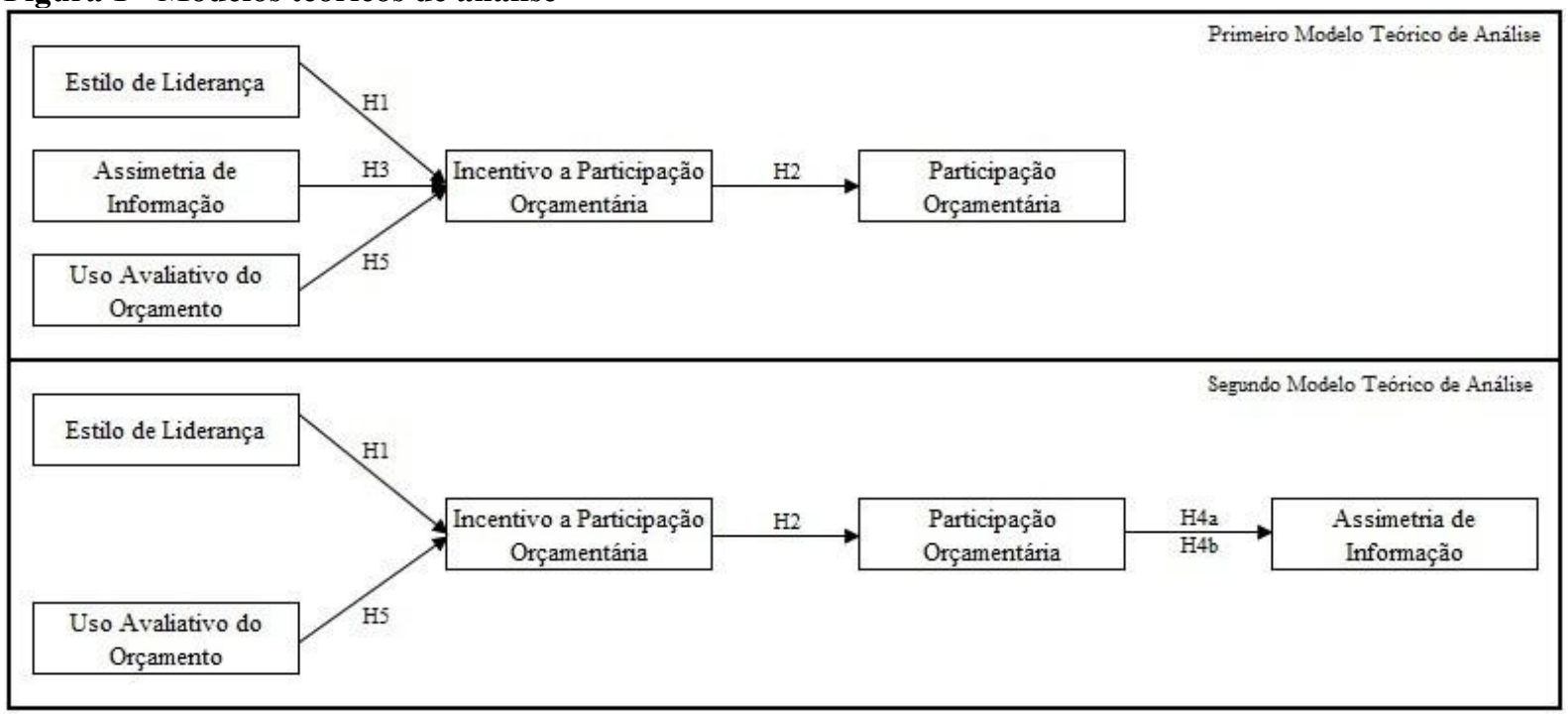

Fonte: elaborado pelos autores.

Os procedimentos metodológicos adotados para o desenvolvimento desta pesquisa são apresentados a seguir.

\section{Método e Procedimentos da Pesquisa}

Define-se esta pesquisa como descritiva, realizada por meio de levantamento, com aplicação de questionário e abordagem quantitativa, pois se utilizou de métodos estatísticos para sua realização: Análise Fatorial Confirmatória e Modelagem de Equações Estruturais. A amostra investigada na pesquisa compreendeu gerentes, analistas, coordenadores de orçamento e controllers que se reportam a um superior em organizações industriais sediadas no Brasil. A partir da utilização da rede de contatos Linkedin foi possível obter o contato (e-mail) de 347 pessoas responsáveis pelo orçamento, os quais receberam o convite para participarem desta pesquisa. O instrumento de pesquisa foi elaborado no Google Docs e posteriormente enviado o link do questionário por e-mail. A amostra não aleatória constituiu-se de 106 respondentes, sendo caracterizada como uma amostra por acessibilidade. Assim, as inferências realizadas nesta pesquisa se limitam aos responsáveis pelo orçamento que se dispuseram a responder voluntariamente o instrumento de pesquisa.

Para a coleta dos dados, utilizou-se de uma versão traduzida e adaptada do questionário desenvolvido por Kyj e Parker (2008). As variáveis utilizadas no questionário incluem questões relacionadas aos antecedentes da participação no orçamento: Estilo de Liderança (EL), Assimetria de Informação (AI), Uso Avaliativo do Orçamento (UO), investigado por aqueles autores. Além disso, abrange questões adaptadas do estudo de Kyj e Parker (2008) sobre o Incentivo a Participação no Orçamento (IPO) e questões desenvolvidas por Milani (1975) para 
a Participação do indivíduo no Orçamento (PO). As afirmativas sobre a temática analisada foram elaboradas a partir de uma escala Likert de sete pontos, que avaliou o nível de concordância dos respondentes em relação a cada afirmativa, em que o nível de discordância máxima indicado era 1 (Discordo Totalmente) e o nível de concordância máxima era 7 (Concordo Totalmente). Antes de aplicado, o questionário traduzido foi avaliado por um professor fluente no ensino da língua inglesa. Posteriormente o instrumento de coleta revisado foi apreciado por dois pesquisadores desta temática, Doutores em Ciências Contábeis, que inferiram sobre o questionário final a ser aplicado na coleta dos dados. Este processo possibilitou a identificação de questões no questionário que, na percepção dos revisores, não estavam claras e poderiam comprometer o entendimento dos respondentes. Deste modo, foram aceitas as contribuições apresentadas e consideradas para a versão final do instrumento utilizado.

A fim de assegurar maior confiabilidade as análises realizadas, para validar o instrumento de pesquisa foram realizados ainda outros dois pré-testes com pessoas que já exerceram a função na área de orçamento. A partir da realização destes pré-testes, identificouse a necessidade de modificar alguns detalhes nas questões relacionadas ao uso avaliativo do orçamento, de modo a deixar mais claro ao respondente o significado das questões elaboradas neste constructo. Os participantes do pré-teste não fizeram parte da pesquisa e não integraram a população em estudo. O instrumento de coleta de dados foi enviado no mês de novembro de 2016. As respostas do questionário foram organizadas em planilha eletrônica de excel para a tabulação e a posterior análise dos dados, com a utilização de técnicas estatísticas.

$\mathrm{Na}$ etapa de análise e interpretação dos resultados, para ambos os modelos teóricos de análise investigados nesta pesquisa (Figura 1), inicialmente realizou-se a Análise Fatorial Confirmatória (AFC), com vistas a testar a confiabilidade, bem como a validade dos constructos selecionados para esta investigação. Posteriormente, operacionalizou-se por meio do software SmartPLS ${ }^{\circledR}$ a Modelagem de Equações Estruturais. O objetivo desta análise é decompor a associação entre as variáveis em diferentes efeitos tanto diretos quanto indiretos, e, além disso, as observações dessas variáveis em um conjunto de relações eventuais (MARÔCO, 2011). Hair Jr. et al. (2009) salientam que o modelo estrutural apresenta as relações entre as variáveis e a quantidade de variância explicada. Nesse sentido, a Modelagem de Equações Estruturais foi adotada com o intuito de se investigar tanto os efeitos de antecedentes a participação orçamentária, como preconizado por Kyj e Parker (2008), como os efeitos consequentes da participação na assimetria informacional, o que foi realizado em uma amostra ainda não investigada, gestores de organizações industriais sediadas no Brasil.

A confiabilidade de cada constructo foi calculada de maneira separada. Um indicador geralmente utilizado para conferir a confiabilidade dos dados é o Alfa de Cronbach (AC). Este teste aceita valores de 0,60 a 0,70 . No entanto, valores abaixo destes também são aceitáveis em pesquisas de natureza exploratória. Este cálculo da confiabilidade a partir do AC não considera os erros nas variáveis. Nesta pesquisa, para a validação dos constructos de mensuração, utilizouse além do coeficiente $\mathrm{AC}$, a Confiabilidade Composta (CC) e a Variância Média Extraída (Average Variance Extracted - AVE). A CC é uma medida de consistência interna das variáveis analisadas e, sugerem-se valores maiores que 0,70 para sua aceitação. No que diz respeito à AVE, esta é uma medida de confiabilidade que indica a quantidade geral de variância nos indicadores, explicada pelo constructo. Para este teste, a literatura recomenda valores superiores a 0,50 (HAIR JR. et al., 2009), o que foi observado nesta pesquisa. Os resultados da análise e interpretação dos dados são descritos a seguir. 


\section{Apresentação e Análise dos Resultados}

\subsection{Estatística Descritiva e Validação dos Modelos Estruturais}

Inicialmente discorre-se a estatística descritiva dos constructos analisados. $\mathrm{Na}$ sequência, apresentam-se os indicadores de confiabilidade, a validade discriminante, a relevância preditiva $\left(\mathrm{Q}^{2}\right)$ e o tamanho do efeito $\left(\mathrm{f}^{2}\right)$ dos constructos. Posteriormente, os modelos estruturais testados e, por fim, o resumo dos resultados obtidos para as hipóteses do estudo. $\mathrm{Na}$ Tabela 1 evidencia-se a estatística descritiva dos constructos pesquisados.

Tabela 1 - Estatística descritiva

\begin{tabular}{c|l|c|c|c|c|c}
\multicolumn{2}{c|}{ Constructos* $^{2}$} & $\begin{array}{c}\text { Total de } \\
\text { Questões }\end{array}$ & $\begin{array}{c}\text { Alcance } \\
\text { Teórico }\end{array}$ & $\begin{array}{c}\text { Alcance } \\
\text { Observado }\end{array}$ & $\begin{array}{c}\text { Média } \\
\text { Geral }\end{array}$ & $\begin{array}{c}\text { Desvio } \\
\text { Padrão }\end{array}$ \\
\hline EL & Estilo de Liderança & 5 & $5-35$ & $5-35$ & 23,59 & 6,38 \\
\hline AI & Assimetria de Informação & 6 & $6-42$ & $12-42$ & 31,24 & 7,45 \\
\hline UO & Uso Avaliativo do Orçamento & 5 & $5-35$ & $13-35$ & 28,87 & 4,56 \\
\hline IPO & Incentivo a Participação Orçamentária & 3 & $3-21$ & $3-21$ & 16,72 & 4,54 \\
\hline PO & Participação Orçamentária & 6 & $6-42$ & $6-42$ & 34,27 & 7,74 \\
\hline
\end{tabular}

*Resultados obtidos a partir da soma das respostas do número total de questões que compõe cada constructo. Fonte: Dados da pesquisa.

De acordo com Hair Jr. et al. (2009), os dados são assimétricos quando apresentam valores fora do intervalo $-1 \mathrm{a}+1$. Nesta pesquisa todos os constructos encontram-se dentro desse intervalo, o que revela que os dados apresentam uma distribuição normal. A partir dos resultados das médias evidenciadas na Tabela 1 , pode-se verificar que os antecedentes da participação orçamentária mediados pelo incentivo à participação do subordinado na elaboração do orçamento, promovem a participação orçamentária. Estas evidências indicam que o estilo de liderança, assimetria de informação e uso avaliativo do orçamento, podem apresentar impactos no sistema orçamentário das organizações pesquisadas, fazendo com que os superiores fomentem a participação dos indivíduos nos processos orçamentários. Contudo, indicam que esta participação difere entre os gestores participantes da pesquisa, o que revela que organizações industriais brasileiras adotam estruturas orçamentárias distintas, mais ou menos participativas.

De modo geral, o maior grau de concordância entre os respondentes em relação às variáveis analisadas, diz respeito à participação orçamentária $(34,27)$ e a assimetria de informação $(31,24)$. No entanto, os questionamentos sobre a participação orçamentária e assimetria de informação também apresentaram a maior divergência entre os respondentes, visto que os resultados indicaram um valor de desvio padrão elevado $(7,74$ e 7,45 respectivamente). Estes resultados revelam que em algumas organizações os níveis de participação orçamentária são diferentes entre os participantes com responsabilidades orçamentárias, o que sugere que em algumas empresas estes responsáveis não compreendem o seu envolvimento nas definições de metas e objetivos orçamentários, bem como, a sua influência em práticas orçamentárias desenvolvidas nas organizações (SHIELDS; SHIELDS, 1998). Também revelam a existência de assimetria informacional nestas organizações, o que reforça a oportunidade de se investigar os efeitos da participação na assimetria como um elemento consequente a participação, em que a assimetria informacional se faz presente no contexto orçamentário, podendo ou não ser reduzida pelos níveis de participação orçamentária existentes na empresa.

A confiabilidade, ou até mesmo ausência de erros aleatórios nas medidas dos constructos analisados, foi avaliada a partir da homogeneidade ou consistência interna dos itens 
utilizados para a sua definição. Para tanto, foram calculados os coeficientes de AVE, CC e AC, como observa-se na Tabela 2.

Tabela 2 - Indicadores de confiabilidade

\begin{tabular}{c|l|c|c|c|c}
\hline \multicolumn{2}{l|}{ Primeiro Modelo Estrutural de Mensuração } & AVE & CC & AC & $\begin{array}{c}\text { Rquare - } \\
\text { R2 }\end{array}$ \\
\hline EL & Estilo de Liderança & 0,623 & 0,868 & 0,786 & - \\
\hline AI & Assimetria de Informação & 0,717 & 0,938 & 0,923 & - \\
\hline UO & Uso Avaliativo do Orçamento & 0,514 & 0,840 & 0,781 & - \\
\hline IPO & Incentivo a Participação Orçamentária & 0,797 & 0,921 & 0,872 & 0,250 \\
\hline PO & Participação Orçamentária & 0,704 & 0,935 & 0,917 & 0,413 \\
\hline \multicolumn{2}{l|}{ Segundo Modelo Estrutural de Mensuração } & AVE & CC & AC & $\begin{array}{c}\text { Square - } \\
\text { R2 }\end{array}$ \\
\hline EL & Estilo de Liderança & 0,623 & 0,868 & 0,786 & - \\
\hline UO & Uso Avaliativo do Orçamento & 0,514 & 0,840 & 0,781 & - \\
\hline IPO & Incentivo a Participação Orçamentária & 0,796 & 0,921 & 0,872 & 0,233 \\
\hline PO & Participação Orçamentária & 0,705 & 0,935 & 0,917 & 0,411 \\
\hline AI & Assimetria de Informação & 0,715 & 0,938 & 0,923 & 0,074 \\
\hline
\end{tabular}

Legenda: AVE - Variância Média Extraída; CC - Confiabilidade Composta; AC - Alfa de Cronbach.

Fonte: Dados da pesquisa.

Segundo os achados apresentados na Tabela 2, verifica-se que no primeiro e no segundo modelo estrutural testado, todos os constructos apresentaram valores acima de 0,50 , ou seja, há uma quantidade geral aceitável de variância nas variáveis explicadas por meio dos constructos. Destaca-se o constructo que abrange questões sobre o incentivo a participação do subordinado no orçamento, visto que apresentou a maior AVE de 0,797 e 0,796 nos dois modelos analisados respectivamente. No que tange a Confiabilidade Composta (CC) todas as dimensões analisadas (primeiro e segundo modelo) ficaram acima de 0,70, conforme sugerido por Hair Jr. et al. (2009), o que revela que todas as variáveis apresentaram ótima consistência interna. Neste teste para os dois modelos, nota-se que a assimetria de informação apresentou a maior consistência interna nas respostas, seguido do constructo da participação orçamentária.

Em relação aos resultados do Alfa de Cronbach, todos os constructos apresentaram valores superiores a 0,70 . Assim, todos os constructos pesquisados apresentaram alto poder de explicação, bem como boa confiabilidade, sendo possível atestar que os constructos demonstraram limites aceitáveis para os testes dos modelos estruturais investigados nesta pesquisa, tanto para o primeiro modelo, quanto para o segundo, que serão apresentados durante a análise dos resultados.

Quanto ao poder de explicação dos modelos, percebe-se que o constructo participação orçamentária apresentou um grau de explicação $\left(\mathrm{R}^{2}\right)$ de $41,30 \%$ e $41,10 \%$ para o primeiro e segundo modelo estrutural respectivamente, o que confere uma razoável explicação desta variável para o modelo analisado. Já o constructo incentivo à participação orçamentária apresentou um poder de explicação menor que o constructo da participação orçamentária nos dois modelos. Na Tabela 3 apresentam-se os achados para a validade discriminante realizada por meio do critério de Fornell e Larcker (1981).

A validade discriminante é considerada a medida que as variáveis de um modelo representam um constructo único e as variáveis do constructo são distintas umas das outras. A partir dos resultados observados na Tabela 3, constata-se que o modelo apresenta validade discriminante, visto que a raiz quadrada da AVE (valores em negrito) é maior que as correlações entre as demais variáveis latentes para os dois modelos estruturais testados. 
Tabela 3 - Validade discriminante

\begin{tabular}{|c|c|c|c|c|c|c|}
\hline \multicolumn{2}{|c|}{ Primeiro Modelo Estrutural de Mensuração } & EL & AI & $\mathbf{U O}$ & IPO & PO \\
\hline EL & Estilo de Liderança & 0,789 & & & & \\
\hline AI & Assimetria de Informação & 0,353 & $\mathbf{0 , 8 4 7}$ & & & \\
\hline $\mathrm{UO}$ & Uso Avaliativo do Orçamento & 0,027 & 0,203 & $\mathbf{0 , 7 1 7}$ & & \\
\hline IPO & Incentivo a Participação Orçamentária & 0,365 & 0,314 & 0,324 & $\mathbf{0 , 8 9 3}$ & \\
\hline $\mathrm{PO}$ & Participação Orçamentária & 0,225 & 0,269 & 0,381 & 0,642 & $\mathbf{0 , 8 3 9}$ \\
\hline \multicolumn{2}{|c|}{ Segundo Modelo Estrutural de Mensuração } & EL & AI & UO & IPO & PO \\
\hline EL & Estilo de Liderança & $\mathbf{0 , 7 8 9}$ & & & & \\
\hline AI & Assimetria de Informação & 0,359 & $\mathbf{0 , 8 4 5}$ & & & \\
\hline $\mathrm{UO}$ & Uso Avaliativo do Orçamento & 0,027 & 0,188 & 0,717 & & \\
\hline IPO & Incentivo a Participação Orçamentária & 0,366 & 0,310 & 0,325 & 0,892 & \\
\hline $\mathrm{PO}$ & Participação Orçamentária & 0,224 & 0,272 & 0,380 & 0,641 & $\mathbf{0 , 8 4 0}$ \\
\hline
\end{tabular}

Fonte: Dados da pesquisa.

Quando esses pressupostos são atendidos, verifica-se que há evidências de validade discriminante, ou seja, de fato têm-se medidas diferentes para construtos distintos (FORNELL; LARCKER, 1981). Para tanto, pode-se revelar que os constructos do modelo analisado são confiáveis e válidos. O próximo passo na análise dos resultados é o exame dos resultados da Relevância Preditiva $\left(\mathrm{Q}^{2}\right)$ e Tamanho do Efeito $\left(\mathrm{f}^{2}\right)$ dos constructos, conforme se evidencia na Tabela 4.

Tabela 4 - Relevância Preditiva $\left(Q^{2}\right)$ e Tamanho do Efeito $\left(f^{2}\right)$ dos constructos

\begin{tabular}{c|l|c|c}
\hline \multicolumn{2}{c|}{ Primeiro Modelo Estrutural de Mensuração } & $\mathbf{Q}^{\mathbf{2}}$ & $\mathbf{f}^{\mathbf{2}}$ \\
\hline EL & Estilo de Liderança & 0,490 & - \\
\hline AI & Assimetria de Informação & 0,598 & - \\
\hline UO & Uso Avaliativo do Orçamento & 0,235 & 0,176 \\
\hline IPO & Incentivo a Participção Orçamentária & 0,599 & 0,251 \\
\hline PO & Participação Orçamentária & 0,576 & $\mathbf{f}^{\mathbf{2}}$ \\
\hline Segundo Modelo Estrutural de Mensuração & $\mathbf{Q}^{\mathbf{2}}$ & - \\
\hline EL & Estilo de Liderança & 0,490 & - \\
\hline UO & Uso Avaliativo do Orçamento & 0,235 & 0,162 \\
\hline IPO & Incentivo a Participção Orçamentária & 0,599 & 0,251 \\
\hline PO & Participação Orçamentária & 0,577 & 0,039 \\
\hline AI & Assimetria de Informação & 0,598 & \\
\hline
\end{tabular}

Fonte: Dados da pesquisa.

A relevância preditiva $\left(\mathrm{Q}^{2}\right)$ objetiva avaliar a precisão do modelo ajustado, tendo como critérios de avaliação valores maiores que zero (HAIR JR. et al., 2014). Já o tamanho do efeito dos constructos ( $\left.\mathrm{f}^{2}\right)$ é um valor que é obtido pela inclusão e exclusão de constructos do modelo (um a um). Neste teste, valores entre 0,02 e 0,15 são considerados pequenos, e valores entre 0,15 e 0,35 são considerados médios, enquanto que valores acima de 0,35 são ponderados como sendo grandes (HAIR JR. et al., 2014). Observa-se, segundo a Tabela 4, que a relevância preditiva $\left(\mathrm{Q}^{2}\right)$ apresentou valores maiores que zero e o tamanho do efeito $\left(\mathrm{f}^{2}\right)$ dos constructos pode ser considerado médio para os dois modelos estruturais testados no estudo. Os resultados das modelagens investigadas são apresentados a seguir.

\subsection{Análise e Discussão dos Resultados}

Os resultados do primeiro teste da modelagem estrutural investigada são apresentados na Figura 2. 


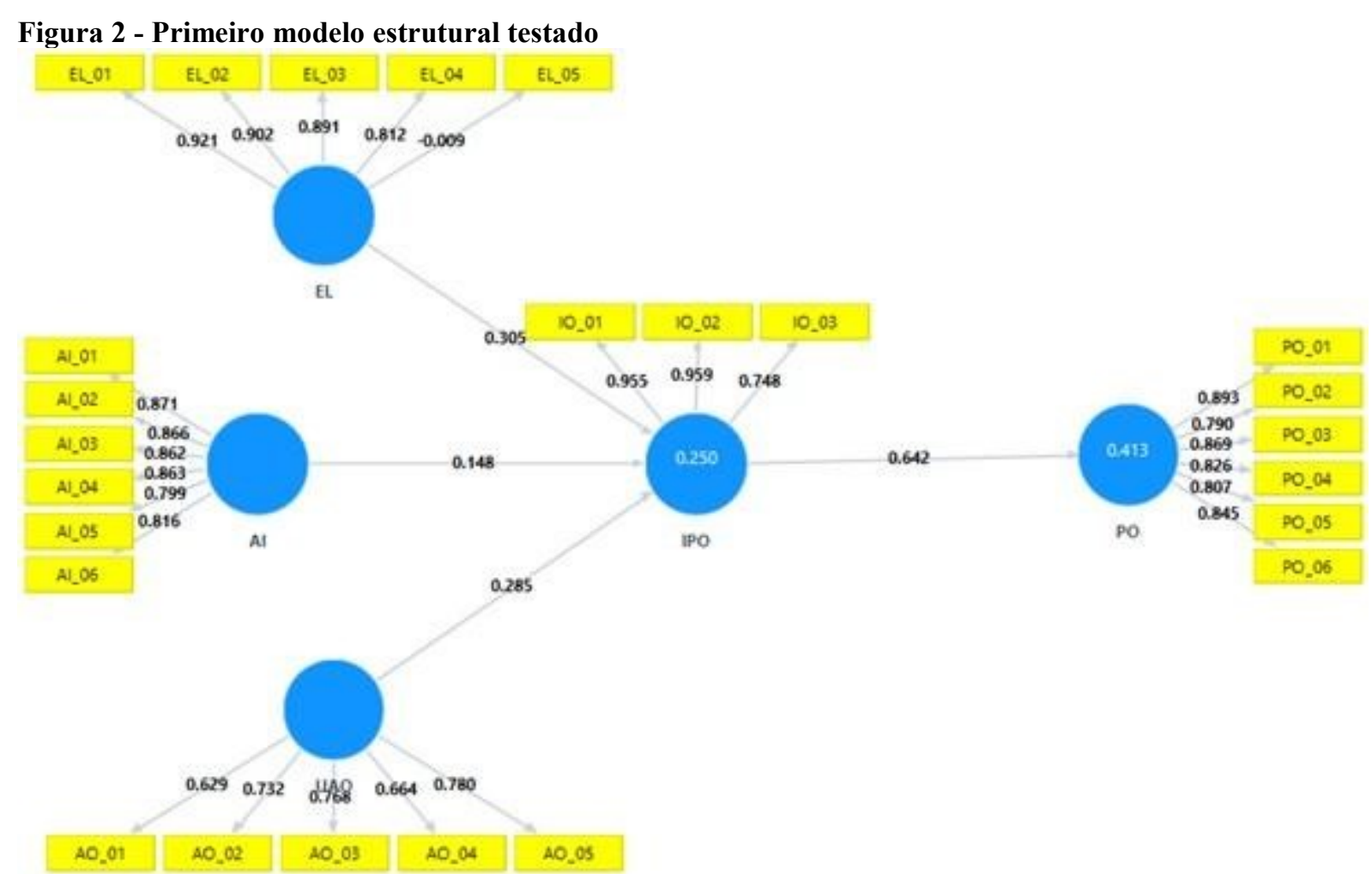

Legenda: EL. Estilo de Liderança; AI. Assimetria de Informação; UAO. Uso Avaliativo do Orçamento; IPO. Incentivo a Participação Orçamentária; PO. Participação Orçamentária.

Fonte: Dados da pesquisa.

A Figura 2 apresenta um resumo das variáveis exógenas (Estilo de Liderança (EL), Assimetria de Informação (AI) e Uso Avaliativo do Orçamento (UAO)), constructos estes que são postulados para afetar a Participação do Orçamento (PO) por meio de um constructo mediador, ou seja, o Incentivo a Participação do Orçamento (IPO), conforme preconizado no modelo teórico de análise proposto por Kyj e Parker (2008). Conforme ressaltam Covaleski et al. (2007), o emprego de diversas perspectivas oferece aos pesquisadores a oportunidade de explicações mais completas, profundas e válidas das práticas orçamentárias nas empresas.

Neste modelo estrutural testado, cada link entre as variáveis possui um coeficiente de caminho que mede o impacto das variáveis antecedentes na explicação da variância em uma variável de resultado. O coeficiente de trajetória busca medir a associação entre as variáveis em termos de desvio padrão, especificamente a mudança na variável de resultado, medida em desvio padrão, associada a uma mudança de um desvio padrão nas variáveis antecedentes. $\mathrm{O}$ valor do coeficiente de caminho é o coeficiente beta padronizado determinado pela regressão da variável de resultado nas variáveis antecedentes analisadas (HAIR JR. et al., 2014).

Conforme os resultados apresentados na Figura 2, nota-se que os antecedentes estilo de liderança $(0,305)$ e uso avaliativo do orçamento $(0,285)$ apresentaram relação estatisticamente significativa com o incentivo a participação no orçamento, resultados estes que corroboram com os achados do estudo de Kyj e Parker (2008). Já a relação proposta entre a assimetria de informação e o incentivo a participação no orçamento, bem como a participação no orçamento não foi suportada nesta pesquisa, visto que não apresentou relação significativa. Este achado vai ao encontro dos resultados encontrados por Kyj e Parker (2008), que também constataram que a assimetria de informação não apresenta relação com o incentivo a participação no orçamento. Contudo, este resultado contrasta com a correlação significativa encontrada por Shields e Young (1993) entre a assimetria da informação e a participação orçamentária. 
Deste modo, pode-se inferir que os antecedentes: estilo de liderança e uso avaliativo do orçamento, mediados pelo constructo do incentivo à participação no orçamento, promovem a participação orçamentária dos subordinados nesse processo, pois o resultado apresentou uma relação de 0,642 no constructo de participação orçamentária. Esta descoberta de uma ligação entre o uso avaliativo do orçamento e a participação no orçamento reflete os resultados encontrados por Lau e Buckland (2000) e Lau e Tan (2003).

No que tange à interpretação dos resultados estatísticos sobre o constructo do incentivo a participação no orçamento e sua ligação com a participação orçamentária, pode-se inferir que estes achados refletem os esforços dos subordinados para participar na definição de normas de desempenho, para garantir que as normas sejam justas e razoáveis nas empresas, o que tende a influenciar positivamente os níveis de participação dos indivíduos nos processos orçamentários.

O estilo de liderança apresentou uma relação positiva com o incentivo do superior a participação no orçamento, o que possibilita suportar a $\mathbf{H}_{1}$ - $\mathbf{O}$ estilo de liderança do superior apresenta uma relação positiva com o incentivo do superior à participação do orçamento. Além disso, pode-se considerar a partir deste achado que os líderes com um estilo de liderança atencioso são susceptíveis de promover a participação do subordinado nas tarefas de orçamentação das empresas. Os achados para a hipótese de pesquisa $\mathbf{H}_{2}$ - O incentivo do superior na participação do orçamento está positivamente relacionado com a participação no orçamento pelo subordinado, indicam que o incentivo apresenta um efeito positivo e significativo na participação orçamentária do subordinado, o que apoia a ideia de que o incentivo é um dos fatores que levam as empresas a terem sucesso no longo prazo.

Estudos anteriores indicaram que o estilo de liderança é considerado um antecedente da participação do orçamento, porém que o estilo de liderança também pode passar a causar conflitos nas empresas entre os superiores e seus subordinados (BAIMAN, 1990; FARIA et al., 2011), o que indica que dependendo do estilo de liderança do superior, isso irá afetar o incentivo a participação orçamentária de forma diferente. Os resultados de Brownell (1983) corroboram com os achados deste estudo, pois encontraram relação positiva e significativa entre o estilo de liderança e a participação no orçamento.

Fleishman (1953) já chamava a atenção para a necessidade de uma preocupação nas empresas para com os problemas de liderança, sendo de suma importância melhorar o comportamento dos supervisores em lidar com os seus subordinados (HARRIS; FLEISHMAN, 1955), visto que isso impacta na participação do orçamento. Além disso, os resultados dos estudos desenvolvidos por Fleishman e Harris (1962), Valenzi e Dessler (1978), Otley e Pierce (1995), Bartolo e Furlonger (2000), Niemeyer e Cavazotte (2016) e Popli e Rizvi, (2016) também revelaram relações significativas entre o estilo de liderança e o envolvimento dos funcionários no processo orçamentário. Deste modo, o papel do líder e seus estilos de liderança são muito importantes para o alcance dos objetivos (KASIATI; MINARSIH; WARSO, 2015) e o envolvimento dos funcionários é visto como uma estratégia chave para o sucesso organizacional (POPLI; RIZVL, 2016).

Diferentemente do observado nas relações anteriores, a assimetria de informação não apresentou relação com o incentivo à participação no orçamento, não sustentando a hipótese $\mathbf{H}_{3}$ - A assimetria da informação apresenta uma relação positiva com o incentivo do superior na participação do orçamento, resultados convergentes aos achados de Kyj e Parker (2008). O estudo desenvolvido por Shields e Young (1993) encontrou resultados positivos que teoricamente suportariam a hipótese de pesquisa analisada neste estudo. Diferenças importantes entre estes estudos podem explicar os resultados divergentes que envolvem o constructo da assimetria de informação. A amostra analisada por Shields e Young (1993) foi composta por grandes empresas que tendem a ser geograficamente dispersas e possuem muitas linhas de produtos. Além disso, a assimetria de informação foi examinada entre a direção central das 
matrizes das empresas e os gestores dos centros de investimento e de lucros imediatamente abaixo da direção central. Assim, para medir o nível de assimetria de informação os controladores tiveram que responder a partir de uma escala a assimetria existente entre os gerentes de nível superior e altos executivos das matrizes. Deste modo, a assimetria de informação foi medida a partir dos níveis mais altos das empresas.

Por outro lado, o estudo de Kyj e Parker (2008) analisou gerentes e supervisores de empresas menores e mais localizadas. Neste caso, a medida de assimetria de informação utilizada neste estudo buscou enfocar as diferenças de informação no contexto de relações entre os superiores/subordinados, sendo assim, a assimetria foi medida no nível individual e não da empresa. Outro aspecto importante a ser considerado é que o estudo de Kyj e Parker (2008) examinou a assimetria de informação entre uma grande variedade de níveis organizacionais, enquanto que Shields e Young (1993) se concentraram nas diferenças de informação entre os gerentes de nível superior e executivos de topo.

Além disso, diversas inferências de autores não puderam ser consideradas no estudo, visto que não se encontrou uma relação da assimetria de informação, mediada pelo incentivo a participação no orçamento com a participação orçamentária, tais como, as constatações de Christensen (1982), Baiman e Evans (1983), Penno (1984), Pope (1984), Young (1985), Shields e Shields (1998), Fisher, Frederickson e Peffer (2002), Zonatto e Lavarda (2013) e Lavarda e Almeida (2013).

Conforme Christensen (1982), Baiman e Evans (1983), Penno (1984), Pope (1984), Young (1985) e Zonatto e Lavarda (2013), a participação orçamentária permite que o subordinado tenha acesso às informações para a realização das tarefas, o que reduziria a assimetria da informação e influenciaria positivamente o seu desempenho no trabalho. Outro estudo que contradiz os achados desta pesquisa é o desenvolvido por Fisher, Frederickson e Peffer (2002), em que os resultados indicaram que a assimetria de informação afeta o processo de negociação e a diferença entre superiores e subordinados. Os resultados do estudo de Zonatto e Lavarda (2013) indicaram que as empresas que possuem um modelo de orçamento sob uma configuração participativa podem reduzir a assimetria e os níveis de estresse no trabalho. Adicionalmente, a explicação de Shields e Shields (1998) também não pode ser considerada nesta pesquisa, pois estes autores ressaltaram que os modelos teóricos sobre a assimetria da informação apresentam uma relação antecedente com a participação orçamentária, visto que a demanda deste orçamento é causada pela incerteza do ambiente.

No que tange ao uso avaliativo do orçamento, este apresentou relação positiva e significativa com o incentivo à participação orçamentária, o que suporta a hipótese $\mathbf{H}_{5}$ - O uso avaliativo do orçamento apresenta uma relação positiva com o incentivo do superior à participação no orçamento. $O$ uso avaliativo do orçamento mediado pelo incentivo à participação do orçamento promove a participação dos subordinados nos processos orçamentários da organização. Os resultados de Brownel e Hirst (1986), Chow, Cooper e Waller (1988) e Shields e Shields (1998) se assemelham com as evidências desta pesquisa, visto que os resultados indicaram que a participação orçamentária possui importância para o planejamento e o controle dos processos gerenciais na organização.

Mia (1988) e Nouri e Parker (1998) destacam que a motivação do subordinado está interligada ao efeito da participação no orçamento e esta participação no processo de orçamentação está associada com um melhor desempenho. As descobertas de Young (1985) corroboram com os resultados desse estudo, visto que os achados revelaram que a participação orçamentária permite que um subordinado possa demostrar suas informações para a realização de suas tarefas e especificar os padrões de desempenho, podendo levar a um maior desempenho e maiores níveis de satisfação no trabalho. As evidências encontradas por Kyj e Parker (2008) se assemelham com estes resultados encontrados, visto que os superiores incentivam a 
participação no orçamento quando as metas orçamentárias são utilizadas na avaliação de desempenho dos subordinados.

Reconhecendo-se que a assimetria informacional poderia não se constituir um elemento antecedente a participação orçamentária, na sequência investigou-se as relações teóricas apresentadas no segundo modelo estrutural elaborado para o estudo. A Figura 3, apresenta os resultados encontrados para a análise destas relações, em que se busca encontrar evidências que permitam responder as hipóteses $\mathrm{H}_{4 \mathrm{a}}$ e $\mathrm{H}_{4 b}$ da pesquisa.

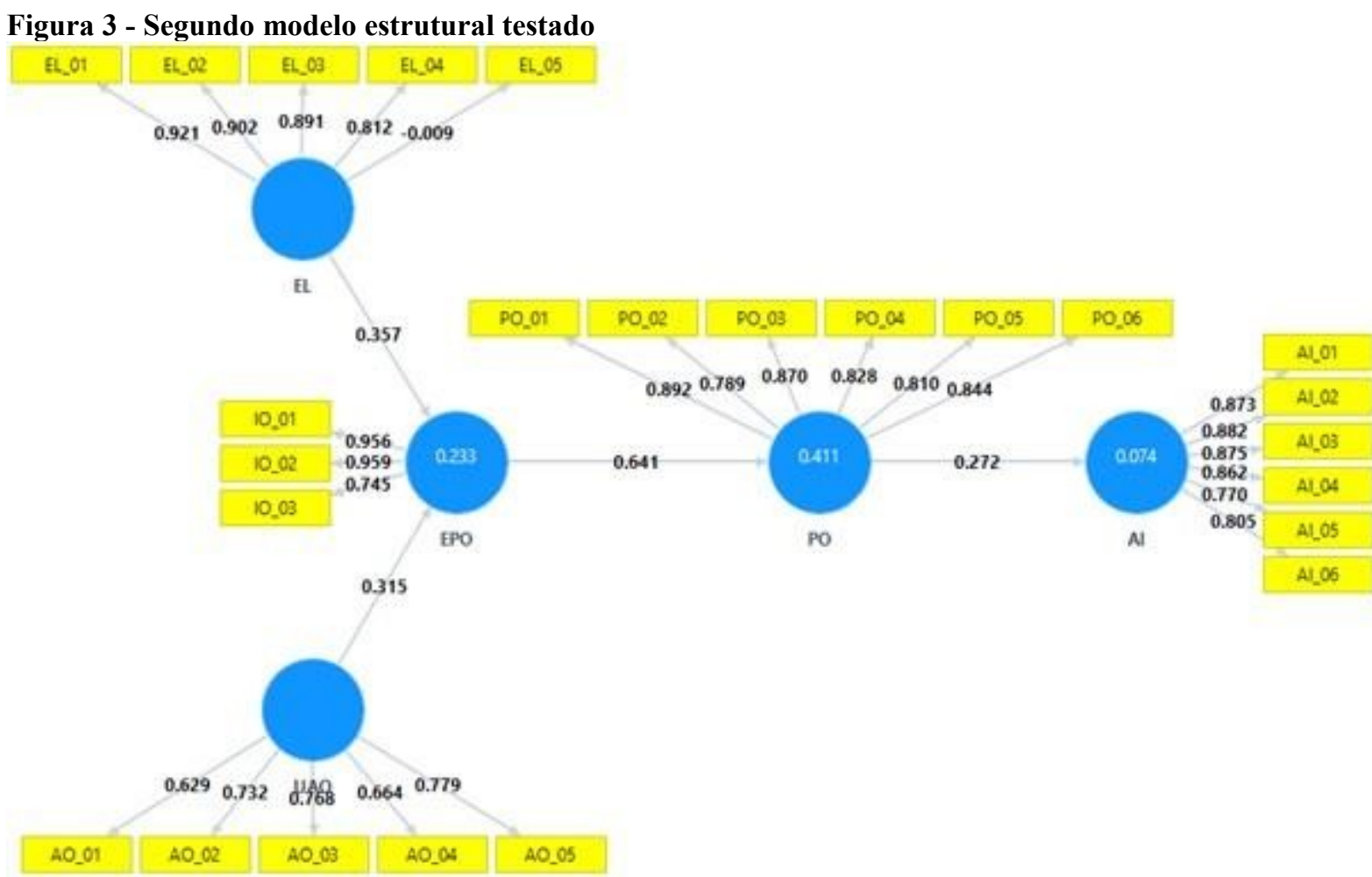

Legenda: EL. Estilo de Liderança; AI. Assimetria de Informação; UAO. Uso Avaliativo do Orçamento; IPO. Incentivo a Participação Orçamentária; PO. Participação Orçamentária.

Fonte: Dados da pesquisa.

Os resultados apresentados na Figura 3, evidenciam novamente que o Estilo de Liderança (EL) e o Uso Avaliativo do Orçamento (UAO), mediados pelo Incentivo a Participação Orçamentária (IPO), apresentam efeitos na Participação do Orçamento (PO). Os resultados evidenciados na Figura 3 demonstram ainda que a participação orçamentária apresentou uma relação positiva e significativa com a assimetria de informação, o que sugere que, na amostra investigada, a participação orçamentária não foi capaz de reduzir/minimizar os níveis de assimetria de informação entre os superiores e os seus subordinados.

Este resultado indica que a maioria dos indivíduos com responsabilidades orçamentárias participantes da pesquisa, mesmo percebendo sua influência nos processos orçamentários de suas organizações, reconhecem que seus superiores continuam com as melhores informações, sendo tecnicamente mais familiarizados com o trabalho, são mais capazes de avaliar o potencial de impacto dos fatores externos, de compreender o que pode ser alcançado, bem como, possuem uma melhor compreensão do potencial de desempenho de suas unidades de trabalho, fatores estes todos relacionados à área de responsabilidade dos subordinados. Os resultados revelaram que o fato de participar dos processos orçamentários não reduziu os níveis de diferença informacional entre a maioria dos superiores e os seus subordinados, visto que as evidências encontradas indicaram que o superior continua possuindo um maior nível de informações dos 
processos orçamentários como um todo.

Nesse sentido, a participação orçamentária apresentou relação positiva e significativa com a assimetria de informação, o que suporta a hipótese de pesquisa $\mathbf{H}_{\mathbf{4 b}}$ - A participação orçamentária tem uma relação positiva com a assimetria de informação. Além disso, a partir destas evidências, a hipótese $\mathbf{H}_{4}$ - A participação orçamentária tem uma relação negativa com a assimetria de informação, não pode ser confirmada diante das respostas obtidas.

Os resultados encontrados pelos estudos desenvolvidos por Dunk (1993), Douglas e Wier (2000) e Lavarda e Almeida (2013), corroboram com a hipótese de pesquisa $\mathrm{H}_{4 \mathrm{~b}}$, visto que também encontraram uma relação positiva e significativa entre a participação orçamentária e a assimetria de informação. Lavarda e Almeida (2013) abordam diante deste resultado, que mesmo a empresa apresentando uma configuração orçamentária participativa, esta condição não minimizou a assimetria informacional existente entre os gestores, pois as respostas indicaram que o gestor/subordinado possuía naquele estudo mais informações do que seu gerente/superior.

Deste modo, se as definições do plano orçamentário em conjunto (superior/subordinado) não apresentaram uma maior integração e comunicação de todos os envolvidos, logo, o compartilhamento de informações será menor (LAVARDA; ALMEIDA, 2013) e até mesmo pode não ocorrer nas organizações. Além disso, Douglas e Wier (2000) salientam, conforme este resultado encontrado nesta pesquisa, que em determinados ambientes de configuração orçamentária participativa, a participação é uma condição necessária, no entanto, não suficiente para a redução da assimetria informacional. Nesta mesma linha, Dunk (1993) abordou que a utilidade da participação orçamentária apresenta pouco apoio para a mitigação dos níveis de assimetria de informação entre o superior e seus subordinados.

Uma possível explicação para tais resultados pode estar relacionada a percepção dos indivíduos de uma necessidade em reter informações. Deste modo, a retenção informacional atuaria como um mecanismo cognitivo de autoproteção (autodefesa) dos indivíduos. Informação e conhecimentos constituem elementos de poder, prestigio e reconhecimento social, bem como de inibição, os quais poderiam justificar a decisão de um determinado indivíduo em não compartilhar a totalidade de informações disponíveis nos processos orçamentários de suas organizações.

Diante dos resultados apresentados, pode-se considerar que a assimetria de informação pode se constituir uma variável consequente da participação orçamentária, presente nos processos orçamentários de uma empresa, a qual poderá vir a ser mitigada pela participação orçamentária, em condições em que os gestores estiverem mais propensos a compartilhar informações, alinhar objetivos e metas orçamentárias e disponíveis a convergir esforços para sua execução. Estes resultados ampliam o conhecimento existente sobre o tema, fornecendo um referencial explicativo aos resultados encontrados na pesquisa desenvolvida por Kyj e Parker (2008), que não validou na íntegra as relações investigadas em seu modelo teórico de análise dos antecedentes a participação orçamentária. A Tabela 5 apresenta um resumo do teste das hipóteses investigadas neste estudo.

Diante do exposto, com base nas análises realizadas, torna-se possível inferir que três hipóteses do primeiro modelo estrutural testado $\left(\mathrm{H}_{1}, \mathrm{H}_{2}\right.$ e $\left.\mathrm{H}_{5}\right)$ foram suportadas, visto que os coeficientes de caminho foram significantes para essas hipóteses. Em contrapartida, a hipótese de pesquisa $\mathrm{H}_{3}$ não pode ser suportada a partir das evidências encontradas também para o primeiro modelo testado. 
Tabela 5 - Teste das hipóteses do estudo

\begin{tabular}{|c|c|c|c|c|c|c|c|}
\hline Hip. & Caminho Estrutural & $\begin{array}{l}\text { Modelo } \\
\text { Testado } \\
\end{array}$ & $\begin{array}{c}\text { Path } \\
\text { Coefficients }\end{array}$ & \begin{tabular}{|c|} 
Standard \\
Error
\end{tabular} & $\begin{array}{c}T- \\
\text { Statistics }\end{array}$ & $\begin{array}{c}P \text { - } \\
\text { Values }\end{array}$ & Resultado \\
\hline \multirow{2}{*}{$\mathrm{H}_{1}$} & \multirow{2}{*}{$\begin{array}{l}\text { Estilo de Liderança } \rightarrow \text { Incentivo a } \\
\text { Participação Orçamentária }\end{array}$} & $1^{\circ} \mathrm{ME}$ & 0,305 & 0,083 & 3,666 & 0,000 & \multirow{2}{*}{ Suportada } \\
\hline & & $2^{\circ} \mathrm{ME}$ & 0,357 & 0,086 & 4,128 & 0,000 & \\
\hline \multirow{2}{*}{$\mathrm{H}_{2}$} & \multirow{2}{*}{$\begin{array}{l}\text { Incentivo a Participação Orçamentária } \\
\rightarrow \text { Participação Orçamentária }\end{array}$} & $1^{\circ} \mathrm{ME}$ & 0,642 & 0,075 & 8,614 & 0,000 & \multirow{2}{*}{ Suportada } \\
\hline & & $2^{\circ} \mathrm{ME}$ & 0,641 & 0,077 & 8,276 & 0,000 & \\
\hline $\mathrm{H}_{3}$ & 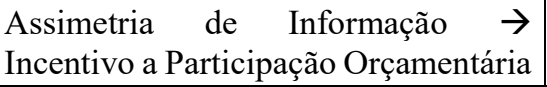 & $1^{\circ} \mathrm{ME}$ & 0,148 & 0,097 & 1,534 & 0,126 & $\begin{array}{c}\text { Não } \\
\text { Suportada }\end{array}$ \\
\hline $\mathrm{H}_{4 b} *$ & $\begin{array}{ll}\text { Participação } \quad \text { Orçamentária } & \rightarrow \\
\text { Assimetria de Informação } & \\
\end{array}$ & $2^{\circ} \mathrm{ME}$ & 0,272 & 0,091 & 2,976 & 0,003 & Suportada \\
\hline \multirow{2}{*}{$\mathrm{H}_{5}$} & \multirow{2}{*}{$\begin{array}{l}\text { Uso Avaliativo do Orçamento } \vec{\rightarrow} \\
\text { Incentivo a Participação Orçamentária }\end{array}$} & $1^{\circ} \mathrm{ME}$ & 0,285 & 0,079 & 3,619 & 0,000 & \multirow{2}{*}{ Suportada } \\
\hline & & $2^{\circ} \mathrm{ME}$ & 0,315 & 0,071 & 4,447 & 0,000 & \\
\hline
\end{tabular}

Legenda: * Hipótese $\mathrm{H}_{4 a}$ não suportada na pesquisa.

Fonte: Dados da pesquisa.

No que tange ao segundo modelo estrutural testado, além das hipóteses suportadas no primeiro modelo $\left(\mathrm{H}_{1}, \mathrm{H}_{2}\right.$ e $\left.\mathrm{H}_{5}\right)$, a $\mathrm{H}_{4 \mathrm{~b}}$ também pode ser suportada no estudo, visto que a hipótese $\mathrm{H}_{4 a}$ não apresentou resultados significativos diante da relação analisada. Assim, a partir destes achados, denota-se que o incentivo a participação no orçamento pode ser considerado um fator mediador dos antecedentes: estilo de liderança e uso avaliativo do orçamento e seus efeitos consequentes na participação dos subordinados no processo orçamentário das organizações analisadas. Além disso, destaca-se que a participação orçamentária influencia a assimetria de informação, contudo, não sendo capaz de eliminar as diferenças informacionais existentes entre o superior e os seus subordinados nos processos orçamentários, o que revela que a assimetria de informação pode ser considerada um fator presente nos processos orçamentários de organizações industriais brasileiras, diferindo entre essas em maior ou menor nível.

\section{Considerações Finais}

Este estudo investigou os motivos pelos quais os superiores incentivam a participação do subordinado nos processos orçamentários de empresas industriais sediadas no Brasil, a partir da análise dos efeitos dos antecedentes a participação orçamentária, sendo estes: estilo de liderança, assimetria da informação e uso avaliativo do orçamento. Os resultados encontrados diante do antecedente estilo de liderança sugerem que os líderes com um estilo de liderança: atencioso, amigável, igualitário, preocupado com o bem-estar pessoal dos subordinados e que promovem explicações, são susceptíveis de promover a participação do subordinado em um cenário de orçamentação. Além disso, o incentivo a participação no orçamento pode mediar a relação entre o estilo de liderança e os resultados no local de trabalho, como a satisfação no trabalho, bem como, a participação orçamentária. Contudo, também revelam que alguns destes gestores, mesmo incentivando a participação de seus subordinados, ainda optam por reter informações, resultando no aparecimento de assimetria informacional nos processos orçamentários.

Outro achado importante desta investigação é que os superiores promovem/incentivam a participação do subordinado quando estes são avaliados por meio de metas orçamentárias. A partir deste antecedente, novamente o incentivo a participação do orçamento pode mediar a relação entre o uso avaliativo do orçamento e os resultados do trabalho, ou seja, a participação no orçamento. No que tange ao antecedente da participação no orçamento assimetria de informação, este não se mostrou relacionado com o incentivo e a participação no orçamento. A partir deste resultado, pode-se considerar que a assimetria de informação não se constituiu, nesta amostra, um antecedente motivador a participação dos indivíduos nos processos 
orçamentários de suas organizações, mas sim um aspecto presente neste contexto, o qual não foi mitigado pelos níveis de participação orçamentária. Isto ocorreu em virtude de alguns gestores superiores possuírem e reterem mais informações, comparativamente a seus subordinados.

A análise considerando a assimetria informacional um fator consequente a participação orçamentária, presente nos processos orçamentários de organizações industriais brasileiras, revelou que a participação orçamentária nem sempre é capaz de mitigar os níveis de assimetria de informação existentes nos processos orçamentários. São os indivíduos os tomadores de suas decisões pessoais, as quais explicitam seu posicionamento, suas crenças e cognições em um contexto de interação social. Logo, revelam a percepção destes indivíduos e seu posicionamento em relação a como deve ser conduzido o processo orçamentário na empresa. Assim, mesmo gestores subordinados percebendo sua influência nos processos orçamentários de suas unidades divisionais, também percebem que a informação disponível neste processo pode ser restrita e parcial.

Deste modo, este estudo aprimorou o modelo de predição dos antecedentes a participação orçamentária desenvolvido por Kyj e Parker (2008), oferecendo um referencial explicativo para a não confirmação dos efeitos da assimetria informacional, como antecedente motivador a participação de gestores subordinados nos processos orçamentários. Estes achados revelam uma contribuição importante desta pesquisa para com os resultados que já se encontram consolidados na literatura do potencial da participação dos indivíduos nos processos orçamentários. No entanto, quando levada a participação orçamentária em consideração com a assimetria de informação, as evidências necessitam ser melhor exploradas em outras amostras, visto que nesta pesquisa, esta relação apresentou-se positiva. Portanto, outras variáveis intervenientes podem ser utilizadas em novos estudos, a fim de se avaliar seus efeitos intervenientes na relação existente entre participação orçamentária, assimetria de informação e desempenho.

No geral, os resultados empíricos encontrados apoiam o referencial teórico proposto nesta pesquisa e podem auxiliar no desenvolvimento de modelos estruturais mais completos, a fim de suportar novas investigações a respeito do papel da participação orçamentária no local de trabalho. Nesse sentido, os achados proporcionam insights teóricos e podem desencadear pesquisas posteriores. O estudo contribui para a literatura uma vez que teve como objetivo examinar por meio de dois modelos teóricos de análise, as relações entre o estilo de liderança, assimetria de informação e uso avaliativo do orçamento, mediadas pelo incentivo a participação no orçamento, com a participação orçamentária, bem como, os efeitos consequentes da participação na assimetria informacional, utilizando medidas já validadas em contextos nacionais e internacionais.

Assim, revela indícios de motivos pelos quais os superiores incentivam a participação do subordinado nos processos orçamentários destas organizações, sendo estes: a obtenção de informações privadas de conhecimento de gestores subordinados, e a definição de objetivos e metas orçamentárias para avaliação de desempenho. Também revelam evidências de que nem todos os antecedentes a participação orçamentária, apontados na literatura comportamental da contabilidade, podem ser confirmados no contexto de atuação de empresas industriais sediadas no Brasil, o que abre perspectivas a realização de novos estudos com o propósito de se investigar tais aspectos.

Além disso, por meio de um modelo alternativo, apresentou-se outra contribuição importante, ou seja, a consideração da assimetria de informação como uma variável consequente a participação orçamentária, visto as evidências conflitantes encontradas na literatura. Estes achados apresentam implicações importantes para o campo de estudos, uma vez que a assimetria informacional tem sido apontada como um elemento que pode influenciar 
o envolvimento dos indivíduos no trabalho, sua motivação, satisfação, além do seu desempenho. Tais relações não foram observadas nesta pesquisa, o que se constitui uma nova oportunidade para a realização de outros estudos. Esta pesquisa também forneceu evidências de relações que se mostraram não significativas, e neste caso positivas, no cenário brasileiro, o que, em modelos mais complexos, pode contribuir para a qualificação dos modelos estruturais de predição, visto que as relações não confirmadas, podem ser preteridas em testes futuros.

Os resultados também oferecem insights para os gestores das empresas, pois o estudo destaca a necessidade de se dar atenção ao estilo de liderança dos superiores, uma vez que este aspecto apresentou influência no incentivo e participação do subordinado no processo orçamentário. Outro ponto a ser observado pelos gestores nas empresas é que os superiores encorajam a participação do subordinado no desenvolvimento do orçamento quando as metas orçamentárias são usadas na avaliação de desempenho dos subordinados, isto é o uso avaliativo do orçamento. Portanto, pode-se concluir que o estilo de liderança, o uso avaliativo do orçamento e o incentivo a participação orçamentária constituem-se antecedentes a participação de gestores subordinados nos processos orçamentários de empresas industriais sediadas no Brasil.

Este estudo se concentrou em verificar os motivos pelos quais os superiores incentivam a participação do subordinado nos processos orçamentários de empresas industriais sediadas no Brasil, a partir da análise dos efeitos de algumas variáveis apontadas na literatura comportamental da contabilidade como antecedentes a participação orçamentária. No entanto, os desejos dos subordinados também podem desempenhar um papel importante na participação do orçamento, visto que os resultados indicaram uma relação significativa e positiva entre o uso avaliativo do orçamento e a participação. Frente este resultado pode-se constatar que isso pode refletir o desejo do subordinado em participar do processo orçamentário quando as metas orçamentárias são levadas em consideração para avaliar o subordinado. Neste caso, a oportunidade para sua participação nos processos orçamentários destas empresas sugere que este constitui-se o momento para a troca de informações, o conhecimento sobre a disponibilidade de recursos, objetivos e metas orçamentárias, bem como a negociação por recursos entre as diferentes unidades divisionais, de modo que se possa além de obter os recursos necessários ao alcance de tais objetivos, elaborar uma previsão orçamentária mais adequada ao contex to organizacional como um todo.

Estes achados reforçam as evidências sobre os papéis informativos do orçamento e sua utilização como um instrumento de avaliação e controle gerencial, capaz de contribuir para com a gestão das organizações, por meio de atividades de planejamento, execução e controle. Nesta pesquisa, a abordagem teórica adotada enfatizou como nível de análise os indivíduos. Contudo, outras perspectivas teóricas de investigação também podem ser observadas quando da realização de novos estudos. Os resultados encontrados revelaram que a relação entre os gestores participantes da pesquisa é enviesada por relações de poder, visto que estes gestores possuem autoridade final sobre a criação do orçamento de suas unidades divisionais e/ou do orçamento final da empresa. A retenção de informações pode representar uma forma de simplificação organizacional na tomada de decisão relacionada aos processos orçamentários, o que também precisa ser observado quando da realização de novos estudos.

Adicionalmente, recomenda-se para pesquisas futuras investigar $o$ desejo do subordinado de participar no desenvolvimento do orçamento ou qualitativamente avaliando as condições em que estes níveis de interesse são maximizados. Sugere-se ainda utilizar outros fatores que podem influenciar o desejo do subordinado na participação do orçamento, tais como, a utilização de bônus baseado no orçamento, satisfação de necessidades de ordem do superior, como a necessidade de influência para o bom andamento da empresa, visto a importância da determinação do orçamento. Outras variáveis revisitadas na base teórica deste 
trabalho também podem ser utilizadas para avaliar os consequentes desta participação, bem como os efeitos da assimetria informacional, como a criação de folga orçamentária, por exemplo. Por fim, é pertinente destacar que os resultados encontrados estão sujeitos a limitações, como podem ser específicos para a amostra utilizada, o desenho transversal da pesquisa e a análise em um único ponto no tempo, não podendo, portanto, ser generalizados.

\section{Referências}

ADLER, R. W.; REID, J. The effects of leadership styles and budget participation on job satisfaction and job performance. Asia-Pacific Management Accounting Journal, v. 3, n. 1, p. 21-46, 2008.

ALMADA, L.; POLICARPO, R. V. S. A relação entre o estilo de liderança e a resistência à mudança dos indivíduos em um processo de fusão. Revista de Gestão, v. 23, n. 1, p. 10-19, 2016. DOI: https://doi.org/10.1016/j.rege.2015.11.002

ARGYRIS, C. The Impact of Budgets on People. A Study Prepared for the Controllership Foundation, Inc. Ithaca, NY: Cornell University, The School of Business and Public Administration, 1952.

BAIMAN, S. Agency research in managerial accounting: A second look. Accounting, Organizations and Society, v. 15, n. 4, p. 341-371, 1990. DOI: 10.1016/03613682(90)90023-n

BAIMAN, S.; EVANS, J. H. Pre-decision information and participative management control systems. Journal of Accounting Research, v. 21, n. 2, p. 371-395, 1983. DOI: $10.2307 / 2490780$

BALDVINSDOTTIR, G.; MITCHELL, F.; NORREKLIT, H. Issues in the relationship between theory and practice in management accounting. Management Accounting Research, v. 21, n. 2, p. 79-82, 2010. DOI: https://doi.org/10.1016/j.mar.2010.02.006

BARTOLO, K.; FURLONGER, B. Leadership and job satisfaction among aviation fire fighters in Australia. Journal of Managerial Psychology, v. 15, n. 1, p. 87-93, 2000. DOI: https://doi.org/10.1108/02683940010305324

BERGAMINI, C. W. Liderança: a administração do sentido. Revista de Administração de Empresas, v. 34, n. 3, p. 102-114, 1994.

BIRNBERG, J. G.; LUFT, J.; SHIELDS, M. D. Psychology theory in management accounting research. In. Chapman, C. S.; Hopwood, A. G.; Shields, M. D. Handbooks of Management Accounting Research, v. 1, n. 4, p. 113-135, 2007. DOI: https://doi.org/10.1016/S1751-3243(06)01004-2

BROWNELL, P. Leadership style, budgetary participation and managerial behavior. Accounting, Organizations and Society, v. 8, n. 4, p. 307-321, 1983. DOI: https://doi.org/10.1016/0361-3682(83)90046-6

BROWNELL, P.; HIRST, M. Reliance on accounting information, budgetary participation, and task uncertainty: tests of a three-way interaction. Journal of Accounting Research, v. 24, n. 2, p. 241-249, 1986. DOI: 10.2307/2491132

BUZZI, D. M.; SANTOS, V. dos; BEUREN, I. M.; FAVERI, D. B. Relação da folga orçamentária com participação e ênfase no orçamento e assimetria da informação. Revista Universo Contábil, v. 10, n. 1, p. 06-27, 2014. DOI:10.4270/RUC.2014101 
CHAPMAN, C. S.; KIHN, L. A. Information system integration, enabling control and performance. Accounting, Organizations and Society, v. 34, n. 2, p. 151-169, 2009. DOI: https://doi.org/10.1016/j.aos.2008.07.003

CHOW, C. W.; COOPER, J. C.; WALLER, W. S. Participative budgeting: Effects of a truthinducing pay scheme and information asymmetry on slack and performance. Accounting Review, v. 63, n. 1, p. 111-122, 1988. DOI: 10.2307/247682

CHONG, V. K.; EGGLETON, I. R. The impact of reliance on incentive-based compensation schemes, information asymmetry and organisational commitment on managerial performance. Management Accounting Research, v. 18, n. 3, p. 312-342, 2007. DOI: https://doi.org/10.1016/j.mar.2007.04.002

CHRISTENSEN, J. The determination of performance standards and participation. Journal of Accounting Research, v. 20, n. 2, p. 589-603, 1982. DOI: 10.2307/2490887

COVALESKI, M.; EVANS III, J. H.; LUFT, J.; SHIELDS, M. D. Budgeting research: three theoretical perspectives and criteria for selective integration. In. Chapman, C. S.; Hopwood, A. G.; Shields, M. D. Handbooks of Management Accounting Research, v. 2, n. 6, p. 587624, 2007. DOI: https://doi.org/10.2308/jmar.2003.15.1.3

DANI, A. C.; ZONATTO, V. C. da S.; DIEHL, C. A. Participação Orçamentária e Desempenho Gerencial: Uma Meta-Análise das Relações Encontradas em Pesquisas Desenvolvidas na Área Comportamental da Contabilidade. Advances in Scientific and Applied Accounting, v. 10, n. 1, p. 54-72, 2017. DOI: 10.14392/ASAA.2017100104

DERFUSS, K. Relating Context Variables to Participative Budgeting and Evaluative Use of Performance Measures: A Meta-analysis. Abacus, v. 51, n. 2, p. 238-278, 2015. DOI: https://doi.org/10.1111/abac.12046

DERFUSS, K. Reconsidering the participative budgeting-performance relation: A metaanalysis regarding the impact of level of analysis, sample selection, measurement, and industry influences. The British Accounting Review, v. 48, n. 1, p. 17-37, 2016. DOI: https://doi.org/10.1016/j.bar.2015.07.001

DOUGLAS, P. C.; WIER, B. Integrating ethical dimensions into a model of budgetary slack creation. Journal of Business Ethics, v. 28, n. 3, p. 267-277, 2000. DOI: 10.2307/25074417

DUNK, A. S. The effect of budget emphasis and information asymmetry on the relation between budgetary participation and slack. Accounting Review, v. 68, n. 2, p. 400-410, 1993. DOI: $10.2307 / 248408$

FARIA, J. A.; GOMES, S. M. S.; DIAS FILHO, J. M.; ALBUQUERQUE, V. A assimetria da informação na elaboração do orçamento: uma análise da produção científica nos periódicos internacionais entre 2005 e 2009. Contabilidade Vista \& Revista, v. 22, n. 2, p. 43-65, 2011.

FISHER, J.; FREDERICKSON, J. R.; PEFFER, S. A. The effect of information asymmetry on negotiated budgets: An empirical investigation. Accounting, Organizations and Society, v. 27, n. 1, p. 27-43, 2002. DOI: https://doi.org/10.1016/S0361-3682(01)00046-0

FLEISHMAN, E. A. The measurement of leadership attitudes in industry. Journal of Applied Psychology, v. 37, n. 3, p. 153-158, 1953. DOI: http://dx.doi.org/10.1037/h0063436

FLEISHMAN, E. A.; HARRIS, E. F. Patterns of leadership behavior related to employee grievances and turnover. Personnel Psychology, v. 15, n. 1, p. 43-56, 1962. DOI: https://doi.org/10.1111/j.1744-6570.1962.tb01845.x 
FORNELL, C.; LARCKER, D. F. Structural equation models with unobservable variables and measurement error: Algebra and statistics. Journal of Marketing Research, v. 18, n. 3, p. 382-388, 1981. DOI: $10.2307 / 3150980$

HAIR JR., J. F.; BLACK, W. C; BABIN, B. J.; ANDERSON, R. E.; TATHAM, R.

L. Análise Multivariada de Dados. 6. ed. Porto Alegre: Bookman, 2009.

HAIR JR., J. F.; HULT, G. T. M.; RINGLE, C.; SARSTEDT, M. A primer on partial least squares structural equation modeling (PLS-SEM). Sage Publications, 2014.

HANSEN, S. C.; VAN DER STEDE, W. A. Multiple facets of budgeting: an exploratory analysis. Management Accounting Research, v. 15, n. 4, p. 415-439, 2004. DOI:

https://doi.org/10.1016/j.mar.2004.08.001

HARRIS, E. F.; FLEISHMAN, E. A. Human relations training and the stability of leadership patterns. Journal of Applied Psychology, v. 39, n. 1, p. 20-25, 1955. DOI:

http://dx.doi.org/10.1037/h0046585

HARRIS, M.; TOWNSEND, R. M. Resource allocation under asymmetric information. Econometrica: Journal of the Econometric Society, v. 49, n. 1, p. 33-64, 1981. DOI: $10.2307 / 1911125$

HARRISON, G. L. The cross-cultural generalizability of the relation between participation, budget emphasis and job-related attitudes. Accounting, Organizations and Society, v. 17, n. 1, p. 1-15, 1992. DOI: https://doi.org/10.1016/0361-3682(92)90033-O

HOPWOOD, A. G. Accounting and Human Behavior. Prentice Hall, 1976.

JAMES, L. R.; BRETT, J. M. Mediators, moderators, and tests for mediation. Journal of Applied Psychology, v. 69, n. 2, p. 307-321, 1984. DOI: http://dx.doi.org/10.1037/00219010.69.2.307

JERMIAS, J.; SETIAWAN, T. The moderating effects of hierarchy and control systems on the relationship between budgetary participation and performance. The International Journal of Accounting, v. 43, n. 1, p. 268-292, 2008. DOI:

https://doi.org/10.1016/j.intacc.2008.06.009

JERMIAS, J.; YIGIT, F. Budgetary participation in Turkey: The effects of information asymmetry, goal commitment, and role ambiguity on job satisfaction and performance. Journal of International Accounting Research, v. 12, n. 1, p. 29-54, 2013. DOI: https://doi.org/10.2308/jiar-50385

KASIATI, M.; MINARSIH, M. M; WARSO, M. Effect of Leadership Style, Internal Communication and Cultural Organization of the Department of Transportation District Employee Performance Puncak Jaya. Journal of Management, v. 1, n. 1, p. 1-14, 2015.

KIDA, T. E. Performance evaluation and review meeting characteristics in public accounting firms. Accounting, Organizations and Society, v. 9, n. 2, p. 137-147, 1984. DOI: https://doi.org/10.1016/0361-3682(84)90003-5

KYJ, L.; PARKER, R. J. Antecedents of budget participation: leadership style, information asymmetry, and evaluative use of budget. Abacus, v. 44, n. 4, p. 423-442, 2008. DOI: https://doi.org/10.1111/j.1467-6281.2008.00270.x

LAPIERRE, L. Imaginário, administração e liderança. Revista de Administração de Empresas, v. 29, n. 4, p. 05-16, 1989. DOI: http://dx.doi.org/10.1590/S003475901989000400002 
LAU, C. M.; BUCKLAND, C. Budget emphasis, participation, task difficulty and performance: the effect of diversity within culture. Accounting and Business Research, v. 31, n. 1, p. 37-55, 2000. DOI: https://doi.org/10.1080/00014788.2000.9729597

LAU, C.; BUCKLAND, C. Budgeting - the Role of Trust and Participation: A Research Note. Abacus, v. 37, n. 3, p. 369-388, 2001. DOI: https://doi.org/10.1111/1467-6281.00092

LAU, C.; TAN. S. The Effects of Participation and Job-Relevant Information on the Relationship Between Evaluative Style and Job Satisfaction. Review of Quantitative Finance and Accounting, v. 21, n. 1, p. 17-34, 2003. DOI: https://doi.org/10.1023/A:1024803621137

LAVARDA, C. E. F.; ALMEIDA, D. M. Participação orçamentária e assimetria informacional: um estudo em uma empresa multinacional. Brazilian Business Review, v. 10, n. 2, p. 74-96, 2013.

MAHLENDORF, M. D.; SCHÄFFER, U.; SKIBA, O. Antecedents of Participative Budgeting-A Review of Empirical Evidence. Advances in Management Accounting, v. 1, n. 1, p. 1-27, 2015. DOI: 10.1108/S1474-787120150000025

MARÔCO, J. Análise estatística com o SPSS Statistics. Report Number, Lda, 2011.

MIA, L. Managerial attitude, motivation and the effectiveness of budget participation. Accounting, Organizations and Society, v. 13, n. 5, p. 465-475, 1988. DOI: https://doi.org/10.1016/0361-3682(88)90017-7

MILANI, K. The Relationship of Participation in Budget-Setting to Industrial Supervisor Performance and Attitudes: A Field Study. The Accounting Review, v. 50, n. 2, p. 274-284, 1975.

MULKI, J. P.; CAEMMERER, B.; HEGGDE, G. S. Leadership style, salesperson's work effort and job performance: the influence of power distance. Journal of Personal Selling \& Sales Management, v. 35, n. 1, p. 3-22, 2015. DOI:

https://doi.org/10.1080/08853134.2014.958157

NIEMEYER, J. R. L.; CAVAZOTTE, F. D. S. C. N. Ethical leadership, leader-follower relationship and performance: a study in a telecommunications company. Revista de Administração Mackenzie, v. 17, n. 2, p. 67-92, 2016. DOI: http://dx.doi.org/10.1590/167869712016

NOURI, H.; PARKER, R. J. The relationship between budget participation and job performance: the roles of budget adequacy and organizational commitment. Accounting, Organizations and Society, v. 23, n. 5-6, p. 467-483, 1998. DOI: sci-hub.tw/10.1016/S03613682(97)00036-6

OTLEY, D. T.; PIERCE, B. J. The control problem in public accounting firms: An empirical study of the impact of leadership style. Accounting, Organizations and Society, v. 20, n. 5, p. 405-420, 1995. DOI: https://doi.org/10.1016/0361-3682(95)00003-R

PARKER, R. J.; KYJ, L. Vertical information sharing in the budgeting process. Accounting, Organizations and Society, v. 31, n. 1, p. 27-45, 2006. DOI:

https://doi.org/10.1016/j.aos.2004.07.005

PENNO, M. Asymmetry of pre-decision information and managerial accounting. Journal of Accounting Research, v. 22, n. 1, p. 177-191, 1984. DOI: 10.2307/2490707

POPE, P. F. Information asymmetries in participative budgeting: A bargaining 
approach. Journal of Business Finance \& Accounting, v. 11, n. 1, p. 41-59, 1984. DOI: https://doi.org/10.1111/j.1468-5957.1984.tb00055.x

POPLI, S.; RIZVI, I. A. Drivers of employee engagement: The role of leadership style. Global Business Review, v. 17, n. 4, p. 965-979, 2016. DOI:

https://doi.org/10.1177/0972150916645701

PRATT, J.; JIAMBALVO, J. Determinants of leader behavior in an audit environment. Accounting, Organizations and Society, v. 7, n. 4, p. 369-379, 1982. DOI: https://doi.org/10.1016/0361-3682(82)90011-3

PRATT, J.; JIAMBALVO, J. Relationships between leader behaviors and audit team performance. Accounting, Organizations and Society, v. 6, n. 2, p. 133-142, 1981. DOI: https://doi.org/10.1016/0361-3682(81)90003-9

RENKO, M.; EL TARABISHY, A.; CARSRUD, A. L.; Brännback, M. Understanding and measuring entrepreneurial leadership style. Journal of Small Business Management, v. 53, n. 1, p. 54-74, 2015. DOI: https://doi.org/10.1111/jsbm.12086

SHIELDS, M. D.; DENG, F. J.; KATO, Y. The design and effects of control systems: tests of direct and indirect-efects models. Accounting, Organizations and Society, v. 25, n. 2, p. 185-202, 2000. DOI: https://doi.org/10.1016/S0361-3682(99)00041-0

SHIELDS, J. F.; SHIELDS, M. D. Antecedents of participative budgeting. Accounting, Organizations and Society, v. 23, n. 1, p. 49-76, 1998.

SHIELDS, M. D.; YOUNG, S. M. Antecedents and consequences of participative budgeting: evidence on the effects of asymmetrical information. Journal of Management Accounting Research, v. 5, n. 1, p. 265-280, 1993.

SOBRAL, F. J. B. de A.; GIMBA, R. de F. As prioridades axiológicas do líder autêntico: um estudo sobre valores e liderança. Revista de Administração Mackenzie, v. 13, n. 3, p. 96121, 2012. DOI: 10.1590/s1678-6971201200030000

VALENZI, E.; DESSLER, G. Relationships of leader behavior, subordinate role ambiguity and subordinate job satisfaction. Academy of Management Journal, v. 21, n. 4, p. 671-678, 1978. DOI: https://doi.org/10.5465/255707

VARGAS, M. I. R. Determinant factors for small business to achieve innovation, high performance and competitiveness: organizational learning and leadership style. ProcediaSocial and Behavioral Sciences, v. 169, n. 20, p. 43-52, 2015. DOI:

https://doi.org/10.1016/j.sbspro.2015.01.284

VIZEU, F. Uma aproximação entre liderança transformacional e teoria da ação comunicativa. Revista de Administração Mackenzie, v. 12, n. 1, p. 53-81, 2011. DOI: $10.1590 / \mathrm{s} 1678-697120110001000$

YOUNG, S. M. Participative budgeting: The effects of risk aversion and asymmetric information on budgetary slack. Journal of Accounting Research, v. 23, n. 2, p. 829-842, 1985. DOI: $10.2307 / 2490840$

YUKL, G. Managerial leadership: A review of theory and research. Journal of Management, v. 15, n. 2, p. 251-289, 1989. DOI: https://doi.org/10.1177/014920638901500207

ZANINI, M. T. F.; SANTOS, M. C. C. dos; LIMA, D. D. F. P. A influência do estilo de liderança consultivo nas relações de confiança e comprometimento no Batalhão de Operações 
Policiais Especiais do Rio de Janeiro. Revista de Administração, v. 50, n. 1, p. 105-120, 2015.

ZONATTO, V. C. da S.; LAVARDA, C. E. F. Evidências dos efeitos da participação orçamentária na assimetria de informação, estresse ocupacional e desempenho no trabalho. Advances in Scientific and Applied Accounting, v. 6, n. 1, p. 92-111, 2013.

\footnotetext{
Agradecimentos:

À Coordenação de Aperfeiçoamento de Pessoal de Nível Superior (CAPES), ao Conselho Nacional de Desenvolvimento Científico e Tecnológico (CNPq) e a Universidade Regional de Blumenau (FURB). Artigo relacionado ao Projeto "Pesquisas em desempenho gerencial de gestores com responsabilidade orçamentária” (Processo: 472195/2014-0).

* Uma versão previa foi apresentada no Congresso ANPCONT 2017
} 